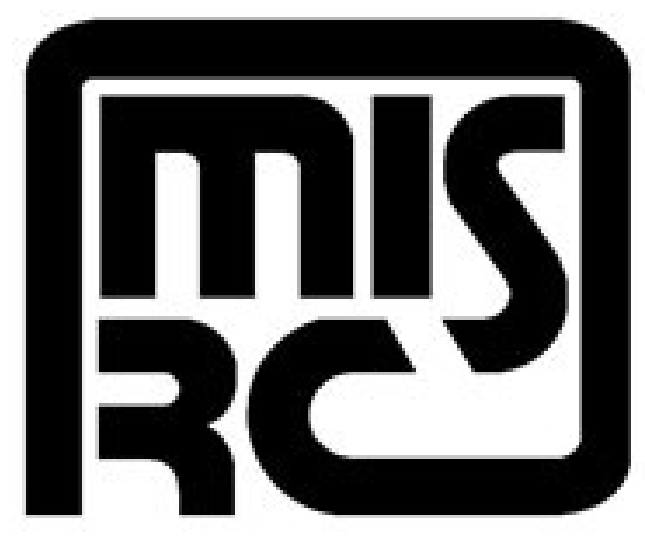

The Nature of Theory in Information Systems

Author(s): Shirley Gregor

Reviewed work(s):

Source: MIS Quarterly, Vol. 30, No. 3 (Sep., 2006), pp. 611-642

Published by: Management Information Systems Research Center, University of Minnesota

Stable URL: http://www.jstor.org/stable/25148742

Accessed: 09/05/2012 21:46

Your use of the JSTOR archive indicates your acceptance of the Terms \& Conditions of Use, available at http://www.jstor.org/page/info/about/policies/terms.jsp

JSTOR is a not-for-profit service that helps scholars, researchers, and students discover, use, and build upon a wide range of content in a trusted digital archive. We use information technology and tools to increase productivity and facilitate new forms of scholarship. For more information about JSTOR, please contact support@jstor.org. 


\section{THE NATURE OF THEORY IN INFORMATION SYSTEMS ${ }^{1}$}

\author{
By: \\ Shirley Gregor \\ School of Accounting and Business Information \\ Systems \\ College of Business and Economics \\ The Australian National University \\ Canberra ACT 0200 \\ AUSTRALIA \\ Shirley.Gregor@anu.edu.au
}

is given for the legitimacy and value of each theory type. The building of integrated bodies of theory that encompass all theory types is advocated.

Keywords: Theory, theory taxonomy, theory structure, information systems discipline, philosophy of science, philosophy of social sciences, interpretivist theory, design theory, design science, explanation, prediction, causality, generalization

\section{Introduction}

The aim of this essay is to examine the structural nature of theory in the discipline of Information Systems. There are a number of grounds for believing that this meta-theoretical exploration is both necessary and timely. Calls continue for "good theory" in IS (Watson 2001) and the development of our "own" theory (Weber 2003). Despite the recognition of the need for theory development, however, there is limited discussion in IS forums of what theory means in IS and what form contributions to knowledge can take.

To place this discussion in context, consider the questions that arise about the bodies of knowledge or theories encompassed in a discipline. These questions fall into a number of interrelated classes ${ }^{2}$ :

1. Domain questions. What phenomena are of interest in the discipline? What are the core problems or topics of interest? What are the boundaries of the discipline?

\footnotetext{
${ }^{2}$ The last three of these four classes have parallels in the three sets of issues distinguished by Godfrey-Smith (2003) for thinking about the philosophy of science: (1) the logical structure of science, (2) epistemological and methodological issues, and (3) scientific thinking, or the social organization
}

\footnotetext{
of science. When thinking about one discipline in particular, we need to add the first class to define the range of phenomena of interest in that discipline.

${ }^{1}$ Allen Lee was the accepting senior editor for this paper. M. Lynne Markus, Michael D. Myers, and Robert W. Zmud served as reviewers.
} 
2. Structural or ontological questions. What is theory? How is this term understood in the discipline? Of what is theory composed? What forms do contributions to knowledge take? How is theory expressed? What types of claims or statements can be made? What types of questions are addressed?

3. Epistemological questions. How is theory constructed? How can scientific knowledge be acquired? How is theory tested? What research methods can be used? What criteria are applied to judge the soundness and rigor of research methods?

4. Socio-political questions. How is the disciplinary knowledge understood by stakeholders against the backdrop of human affairs? Where and by whom has theory been developed? What are the history and sociology of theory evolution? Are scholars in the discipline in general agreement about current theories or do profound differences of opinion exist? How is knowledge applied? Is the knowledge expected to be relevant and useful in a practical sense? Are there social, ethical, or political issues associated with the use of the disciplinary knowledge?

Each of these classes of questions has received attention. Examination of each category, however, shows that questions falling into the second category have received limited treatment in the extant literature. Each of these classes of questions is considered in turn, leaving the second category until last.

With respect to the first category, questions about the domain of interest of IS research have remained a topic of interest since the inception of the discipline. Argument about the definition of management information systems dates back to the 1970s (Benbasat 2001) and many writers have debated aspects of our domain identity since that time. A selection of articles illustrates the range and history of this stream of debate. Weber (1987) was concerned with identifying the unique nature of IS that distinguished it from other disciplines. Orlikowski and Iacono (2001) argued for attention to the information technology artifact as the core subject matter of the IS discipline. Benbasat and Zmud (2003) proposed a core set of phenomena to define the IS field, generating further debate in a series of articles in Communications of the Association of Information Systems (2003, Volume 12).

Epistemological questions, in the third category, have also received considerable attention. Numerous articles argue the merits of different paradigms for conducting research in IS. Frequently, debate is framed in terms of distinctions between positivist and interpretivist paradigms (for example, see Orlikowski and Baroudi 1991) or between qualitative and quantitative methods. Some have argued for pluralism in methods (Mingers 2001) or for integrating approaches (Lee 1991). There has been little or no recognition to date in IS of the view that the research approach adopted could vary with different types of theory in IS, which is a view underlying this essay.

Socio-political questions, in the fourth category, address diverse issues. Into this category fall questions concerning the historical development of scientific thought in a disciplinary community (as in Kuhn 1996). An example in Information Systems is the analysis of how the interpretivist paradigm has emerged historically in contrast to positivism (Walsham 1995). There is also discussion of political, power, and prestige issues for the discipline. The benefits and costs of diversity in IS research to the discipline have been considered by Benbasat and Weber (1996) and Robey (1996). Questions of relevance to practice of IS research also fall into this category. Further, what is termed critical theory explicitly addresses ethical and moral questions, by seeking to be emancipatory and bring about improvements in the human condition (see Ngwenyama and Lee 1997).

Returning to questions in the second category, discussion of the structural nature or ontological character of theory in Information Systems is scattered and there is scanty recognition that these questions are even of interest. Here the word ontology is used in the sense that it refers to a language for talking about the nature and components of theory (for example, the different types of statements that are incorporated). Many IS researchers who use the word theory repeatedly in their work fail to give any explicit definition of their own view of theory. A number of papers that discuss different research paradigms (for example, Klein and Myers 1999; Mingers 2001) offer little in the way of definitions or discussion of the nature of theory or types of knowledge that can be expected to result from different research approaches. Recognition that different types of theory exist can be found in some proponents of constructive or design theory (Iivari 1983; Markus et al. 2002; Walls et al. 1992). A wider view on theory and knowledge types is found in only a handful of papers in IS (Cushing 1990; Gregor 2002a 2002b; Iivari 1983; Markus and Robey 1988).

Table 1 presents examples of theories in IS of different ontological types to demonstrate that multiple views of theory exist. These initial examples are presented briefly. Further delineation of these views and more is the raison d'etre of this essay. 
Table 1 Some Differing Views of Theory in Information Systems

Theory as statements that say how something should be done in practice:

An early textbook by Davis and Olson (1985) articulates the way in which MIS should be designed, implemented and managed. This theory provides prescriptions to be followed in practice, with the implicit expectation that the prescribed methods will in some sense be "better" than alternatives (Cushing 1990).

Theory as statements providing a lens for viewing or explaining the world:

Orlikowski and Robey (1991) drew on structuration theory and empirical work to construct a theory in which the organizational consequences of IT are viewed as the products of both material and social dimensions. Such theory is seen as a desirable end product; formal testing of such a theory is not envisaged (Walsham 1995).

Theory as statements of relationships among constructs that can be tested:

The technology acceptance model (Davis 1986) posits that two particular beliefs on the part of users, perceived usefulness and perceived ease-of-use, are of primary relevance for computer acceptance behaviors. This theory leads to testable propositions that can be investigated empirically (see Davis et al. 1989).

Examination of what is meant by theory occurs in other disciplines. An issue of the Academy of Management Review (1989, Volume 14, Number 4), focused on theory and theory development. Similarly, an issue of Administrative Science Quarterly (1995, Volume 40, Number 3) contained articles about what theory is, what theory is not, and how theorizing occurs. Descriptions of theory in the social sciences can also be found in Dubin (1978), Freese (1980), Kaplan (1964), Merton (1967), and Weick (1989). More established disciplines have considerable histories of enquiry into the nature of theory. In the philosophy of science there has been discussion of scientific knowledge and the formulation of theory over a very long period (for example, Hume 1748; Locke 1689; Nagel 1979; Popper 1980). Fundamental ideas from this prior work are drawn upon in this essay, but they are adapted for the IS context.

It is important to examine the nature of theory in IS separately from other disciplines as the four classes of questions depicted earlier are interrelated. The domain of interest for a discipline can be expected to influence the nature of its theory. Theory in mathematics and music, for example, means different things and knowledge is developed, specified, and used in different ways. Thus, the nature of theory in IS could differ from that found in other disciplinary areas. A characteristic that distinguishes IS from other fields is that it concerns the use of artifacts in human-machine systems. Lee (2001, p iii) uses these words:

research in the information systems field examines more than just the technological system, or just the social system, or even the two side by side; in addition, it investigates the phenomena that emerge when the two interact.

Thus, we have a discipline that is at the intersection of knowledge of the properties of physical objects (machines) and knowledge of human behavior. IS can be seen to have commonalities with other design disciplines such as architecture or engineering, which also concern both people and artifacts, or with other applied disciplines such as medicine, where the products of scientific knowledge (such as drugs or treatments) are used with people. To understand IS, theory is required that links the natural world, the social world, and the artificial world of human constructions. Thus, the body of knowledge that is needed draws on natural science, social science and what has been termed design science (Cross 2001; Hevner et al. 2004; March and Smith 1995; Simon 1996). The attributes of such a body of knowledge are worthy of exploration, which is the aim of this essay.

Thinking clearly about the nature of theory in Information Systems has significance for research and practice. Our leading journals expect that published research articles will have a strong grounding in theory (MISQ 2004). Developing theory is what we are meant to do as academic researchers and it sets us apart from practitioners and consultants. In addition, there is the view that "nothing is so practical as a good theory" (Lewin 1945). Theories are practical because they allow knowledge to be accumulated in a systematic manner and this accumulated knowledge enlightens professional practice. 
Personal experience with doctoral students in particular suggests that they often have limited understanding of what is meant by theory. Exposure to conflicting or simplistic descriptions of different research paradigms (for example, interpretivism versus positivism) sometimes leads to confusion. The distinction made earlier among the different classes of questions about research suggests that pieces of the puzzle these novice researchers are facing are missing. The discussion of differences among paradigms is frequently framed around epistemology and the practice of doing research in a community and the possibility that there may be different types of theory appropriate in different circumstance is not explored. An initial premise for the paper is that different types of theory exist in Information Systems and that all can be valuable. The exploration of theory that follows has been framed to be inclusive and does not depend on the adoption of a specific epistemological commitment (that is, how knowledge is acquired and justified). The paper is intended to be of interest to a range of scholars with different personal preferences for research approaches.

The remainder of this paper proceeds as follows. First, it considers general notions of theory in more detail, including different conceptions of causality, explanation, and generalization, which are central to different ways of developing and expressing knowledge. An argument is made that an appropriate taxonomy for IS depends on classifying theories with respect to the degree and manner in which they address four central goals of theory: analysis, explanation, prediction and prescription. The five different types of IS theory distinguished are labeled: (1) theory for analyzing, (2) theory for explaining, (3) theory for predicting, (4) theory for explaining and predicting (EP theory), and (5) theory for design and action. The different types of theory are interrelated and some comprehensive, well-developed bodies of theory could include components from all the types of theory discussed. Illustrations of relevant work in IS are provided under each heading, as are related research methods (briefly), and the form a contribution to knowledge could take. The applicability of the taxonomy is demonstrated by classifying a sample of articles from recent journal issues. The paper concludes with a discussion of questions that arise from consideration of these different views of Information Systems theory and suggestions for further work.

\section{About Theory}

This section presents underlying ideas relevant to theory to preface the subsequent discussion of theory in Information Systems. It is necessary to express these ideas to show the underlying philosophical positions on which the essay relies.
Issues discussed include the nature of theory in general, the need for generalization, the nature of causality and the core goals of explanation and prediction. It is impossible in a single paper to condense the extensive discussion of these topics over many hundreds of years into a meaningful representation of all that has been said. The approach adopted is to give an outline of the perspectives considered and to highlight those differences in thought that are intimately connected with different approaches to theory, as well as some important commonalities.

A wide rather than a narrow view of theory is taken so that the subject matter of the essay is not restricted. Dictionary definitions show that the word theory can take on many meanings, including "a mental view" or "contemplation," a "conception or mental scheme of something to be done, or the method of doing it; a systematic statement of rules or principles to be followed," a "system of ideas or statements held as an explanation or account of a group of facts or phenomena; a hypothesis that has been confirmed or established by observation or experiment, and is propounded or accepted as accounting for the known facts; statements of what are held to be the general laws, principles, or causes of something known or observed," a "mere hypothesis, speculation, conjecture" (OED 2004). Thus, the word theory will be used here rather broadly to encompass what might be termed elsewhere conjectures, models, frameworks, or body of knowledge.

\section{Different Perspectives on Theory}

Differences in views of theory depend to some degree on philosophical and disciplinary orientations, yet there are also commonalities. This essay draws upon writings from the philosophy of the natural sciences, the social sciences, from the interpretivist tradition, and from the sciences of the artificial, all of which are relevant to Information Systems.

In general, philosophers of science writing in the tradition of the physical or natural sciences are likely to see theory as providing explanations and predictions and as being testable. For example, Popper $^{3}$ (1980) held that theorizing, in part, involves the specification of universal statements in a form that enables them to be tested against observations of

\footnotetext{
${ }^{3}$ Popper was an effective critic of Marxism and Freud's psychoanalytic theories and was the first insightful critic of logical positivism. Popper's contributions to the philosophy of science continue to be significant Godfrey-Smith (2003) saw that he had an appeal to many working scientists and was regarded as a hero by many. Magee (1998, p. 256) places Popper among the leading philosophers of the $20^{\text {th }}$ century, along with Russell, Wittgenstein, and Heidegger, and believes that there will be continued discovery and development of his positive views in comparison with his critiques.
} 
what occurs in the real world. Popper described theory as follows (p. 59):

Scientific theories are universal statements. Like all linguistic representations they are systems of signs or symbols. Theories are nets cast to catch what we call "the world"; to rationalize, to explain and to master it. We endeavor to make the mesh even finer and finer.

Similar views of theory can be found in the social sciences. Doty and Glick (1994, p. 233), writing about typologies as a form of theory in organizational studies, thought that the minimal definition of a theory was that it must meet three primary criteria: (1) constructs must be identified; (2) relationships among these constructs must be specified; and (3) these relationships must be falsifiable (that is, able to be tested).

The philosophy of science offers a rich variety of views, which continue to develop (see Godfrey-Smith 2003). One specific and rather narrow position, that of logical positivism, has had a lingering influence on the manner in which theory is regarded by some philosophers of science. Logical positivism was developed in Europe after World War I by what was known as the Vienna Circle. At the base of logical positivism is the famous Verification Principle: only assertions that are in principle verifiable by observation or experience can convey factual information. Experience was thought to be the only source of meaning and the only source of knowledge (Magee 1998). Many philosophers of science regard logical positivism as defunct (Passmore 1967) and Popper takes credit for "killing" it as early as 1934 (Popper 1986). However, traces of logical positivism can still be detected in the philosophy of science: for example, in the reluctance to refer to causality in theoretical statements (see Dubin 1978), causality not being directly observable.

The intrepretivist tradition steers researchers toward a different outlook, where the primary goal is not to develop theory that is testable in a narrow sense (although its validity or credibility may still be assessed), but in

understanding the complex world of lived experience from the point of view of those who live it. This goal is variously spoken of as an abiding concern for the life world, for the emic point of view, for understanding meaning, for grasping the actor's definition of a situation, for Verstehen. The world of lived reality and situation-specific meanings that constitute the general object of investigation is thought to be constructed by social actors (Schwandt 1994, p. 118).
Many of the ideas in this approach stem from the German intellectual tradition of hermeneutics and the Verstehen tradition in sociology, from phenomenology and from critiques of positivism in the social sciences. Knowledge in this paradigm takes on a different perspective.

Knowledge consists of those constructions about which there is a relative consensus (or at least some movement towards consensus) among those competent (and in the case of more arcane material, trusted) to interpret the substance of the construction. Multiple "knowledges" can coexist when equally competent (or trusted) interpreters disagree (Guba and Lincoln 1994, p. 113).

A further approach to theory is evident when the concern is with the construction of technological artifacts. The classic work that treats technology or artifact design as a special prescriptive type of theory is Herbert Simon's The Sciences of the Artificial (1996) first published in 1969. Simon (p. xii) notes that in an earlier edition of his work he described a central problem that had occupied him for many years:

\section{How could one construct an empirical theory?}

I thought I began to see in the problem of artificiality an explanation of the difficulty that has been experienced in filling engineering and other professions with empirical and theoretical substance distinct from the substance of their supporting sciences. Engineering, medicine, business, architecture and painting are concerned not with the necessary but with the contingent- not with how things are but with how they might be - in short, with design.

An ontological position is adopted in this essay that is consistent with a number of these different conceptions of theory. Theory is seen as having an existence separate from the subjective understanding of individual researchers. This position corresponds to ideas expressed by both Habermas and Popper. Habermas (1984) recognizes three different worlds: the objective world of actual and possible states of affairs, the subjective world of personal experiences and beliefs, and the social world of normatively regulated social relations. These three worlds are related to Popper's Worlds 1,2 , and 3 (Popper 1986). World 1 is the objective world of material things; World 2 is the subjective world of mental states; and World 3 is an objectively existing but abstract world of man-made entities: language, mathematics, knowledge, science, art, ethics, and institutions. Thus, theory as an abstract entity belongs to World 3 . An individual can have a subjective view of what a theory means, at which point an 
understanding of the theory resides in a personal World 2. This essay, however, is concerned with theory as World 3 entities, existing outside an individual mind (as, for example, in journal articles).

To sum up, this discussion of different perspectives on theory at a general level shows theories as abstract entities that aim to describe, explain, and enhance understanding of the world and, in some cases, to provide predictions of what will happen in the future and to give a basis for intervention and action. The following sections explore the fundamental goals of explanation and prediction in more depth, as well as the related issues of causality and generality.

\section{Generalization}

A number of different views of theory are encompassed in this essay with a view to being inclusive. There is still a limit, however, to what is classed as theory. Abstraction and generalization about phenomenon, interactions, and causation are thought to be at the core of a theory. We do not regard a collection of facts, or knowledge of an individual fact or event, as theory. "Data are not theory" (Sutton and Staw 1995 , p. 374), although data may form the foundation for theoretical development. For this reason, the word knowledge when used in this essay does not refer to knowledge of specific events or objects, but means body of knowledge, or theoretical knowledge.

Views differ on the degree to which generalization or universality is required in theory. Popper's (1980) view is that the natural sciences should aim at strictly universal statements and theories of natural laws (covering laws), although these laws can never be held with certainty. ${ }^{4}$ The notion of prediction entails some conception of generality. In order to predict what will happen in the future, we need a generalization that includes future events.

The possibility of true "laws" similar to the laws of nature in social affairs is thought unlikely (Audi 1999, p. 705; Cook and Campbell 1979, p. 15; Hospers 1967, p. 232) primarily because of the very large number of conditions $\left(X_{n}\right)$ that might impact on any outcome (Y). Nevertheless, we expect in the social sciences (and IS) that theory should still include generalizations to some degree.

\footnotetext{
${ }^{4}$ Examples of natural laws are Boyle's Law or the law of gravity or $e=m c^{2}$. Popper showed these laws are not empirically verifiable, acknowledging that David Hume had made this observation two and a half centuries before. The problem is the problem of induction: from no finite number of observations, however large, can any unrestrictedly general conclusion be drawn that would be defensible in logic.
}

Theories can be classified by their level of generalization. Meta-theory is at a very high level of abstraction and provides a way of thinking about other theories, possibly across disciplines. Giddens (1984) describes his structuration theory as being a meta-theory. Examples of theories of this nature in Information Systems are not readily apparent, although this essay is one example, being a "theory of theories," and Markus and Robey's (1988) work is another. Theories with sweeping generalizations that are relatively unbounded in space and time are referred to as grand theories (Bacharach 1989). Weber argued that IS is in need of such powerful, general theories that recognizably belong to the discipline, a motivation for his work with Yair Wand on theories of representation (Weber 1997).

The generality of a theory is also indicated by its breadth of focus (Neuman 2000). Substantive theory is developed for a specific area of inquiry, such as delinquent gangs, strikes, divorce, or race relations, based on analysis of observations and is contrasted with formal theory, which is developed for a broad conceptual area such as deviance, socialization, or power. Another term used is mid-range theory, referring to theory that is moderately abstract, has limited scope, and can easily lead to testable hypotheses. Merton (1968) saw midrange theory as particularly important for practice disciplines.

Definition of the level of generality or scope of a theory includes specifying the boundaries within which it is expected to hold and providing the qualifying words, the modal qualifiers, that are used in theoretical statements (words like some, every, all, and always). For example, we could specify a theory about information system failure and say that it had boundaries in that it applied only to large and complex systems. A very general theory might have statements that applied to all systems, where "all" is a modal qualifier.

The level of generality has not been used in this essay as a primary characteristic for distinguishing theory types. The processes by which generalizations are developed may differ with the tradition in which work is carried out (see Lee and Baskerville 2003), yet there appears to be reasonably wide acknowledgement among researchers of many persuasions that varying degrees of generality are possible in theories. Theories in each of the five theory types distinguished in this essay could be subjected to secondary classification on the basis of the level of generality to give a two-dimensional classification scheme-a potential area for further work.

\section{Causality}

The idea of causality, or the relation between cause and event, is central to many conceptions of theory. When theory is 
taken to involve explanation, it is intimately linked to ideas of causation. Often, to ask for an explanation of an event is to ask for its cause. Similarly, the ability to make predictions from theory can depend on knowledge of causal connections. The concept of causality is extremely problematic but is of fundamental philosophical importance. The $18^{\text {th }}$ century Scottish philosopher, David Hume, for example, pointed out that we are unable to see or prove that causal connections exist in the world, though we continue to think and act as if we have knowledge of them (Norton 1999, p. 400). Kant's (1781) position was that understanding in terms of cause and effect was an a priori characteristic of the human mind underlying all human knowledge.

There are many ways of reasoning about causality and to some extent different types of theory reflect different ways of ascribing causality in the phenomena we observe around us and the different types of explanation that arise. An important point, however, is that the various arguments for causality are not mutually exclusive and at different times and in different circumstances we will rely on different reasons for ascribing causality. Four prominent approaches to the analysis of event causation can be distinguished (see Kim 1999):

1. Regularity (or nomological) analysis. Universal regularity gives rise to universal or covering laws. "There are some causes, which are entirely uniform and constant in producing a particular effect; and no instance has ever been found of any failure or irregularity in their in their operation" (Hume 1748, p. 206). This type of regularity is sought in the natural sciences, with examples of covering laws being Boyle's Law and Ohm's Law in physics. Many believe this type of regularity should not be expected or sought in the social sciences (for example, Little 1999).

2. Counterfactual analysis. Under this approach, what makes an event a cause of another is the fact that if the cause had not occurred, the event would not have (the cause is a necessary condition). If counterfactuals are understood in terms of covering laws, then counterfactual analysis may turn into a form of regularity analysis.

3. Probabilistic causal analysis. This type of causality was recognized by Hume $(1748$, p. 206) with an entertaining example. Compared to universal laws, "there are other causes, which have been found more irregular and uncertain; nor has rhubarb always proved a purge, or opium a soporific to everyone, who has taken these medicines." This view of causal analysis is thought to be suited to the social sciences, where the lack of a closed system and the effects of many extraneous influences make other analy- sis difficult to undertake. "To say that $\mathrm{C}$ is the cause of $\mathrm{E}$ is to assert that the occurrence of $\mathrm{C}$, in the context of social processes and mechanisms $F$, brought about $\mathrm{E}$, or increased the likelihood of E" (Little 1999, p. 705).

4. Manipulation or teleological causal analysis. In this view, a cause is an event or state that we can produce at will, or otherwise manipulate to bring about a certain other event as an effect. This analysis relies on an everyday understanding of a cause as an act by an intentional agent, for example, flicking a switch causes a light to turn on.

Cook and Campbell (1979) give a more detailed coverage of causality, although they believe that "The epistemology of causation, and of the scientific method more generally, is at present in a productive state of near chaos" (p. 10). They present Mill's criteria for causality as being of practical use: (1) the cause has to precede the effect in time, (2) the cause and effect must be related, and (3) other explanations of the cause-effect relationship have to be eliminated. Pearl (2000) points out that statisticians (including Karl Pearson) have avoided or argued against the concept of causality altogether, because it is a mental construct that is not well-defined, preferring to deal only with correlations and contingency tables.

Different approaches to theorizing concern themselves with causality to varying degrees and rely on different ways of reasoning about causality for explanations, as seen in the following section.

\section{Explanation and Prediction}

Central to many understandings of theory are the twin goals of explanation and prediction. These goals can be recognized in Popper's view of theory above, and also in the views of Nagel (1979), who sees the distinctive aim of the scientific enterprise as being theories that offer systematic and responsibly supported explanations.

Explanation is closely linked to human understanding, as an explanation can be provided with the intent of inducing a subjective state of understanding in an individual. The nature of explanations has been studied in the philosophy of science (see, for example, Achinstein 1983; Craik 1943; Hempel and Oppenheim 1948; Nagel 1979), in relation to everyday reasoning and the nature of argumentation (see Toulmin 1958; Toulmin et al. 1979), as well as in the subbranches of IS relating to knowledge-based systems (see Gregor and Benbasat 1999). The relationship between scientific explanation and human understanding is also a subject of interest (see, for example, Friedman 1974). 
Approaches to explanation in the philosophy of science can be distinguished in terms of the underlying mode of reasoning about causality, and views on this matter have changed considerably over the last 50 years (Mayes 2004). Two broad approaches to offering explanations can be contrasted. First, a particular fact or event is explained by pointing out the scientific law that governs its occurrence. This "covering law theory of explanation" was developed by Hempel and Oppenheim (1948) and is a tenet of logical empiricist philosophy. To explain something is merely to show how to derive it in a logical argument from premises that include a covering law. A number of problems have been detected with this approach, one of which is the asymmetry problem, illustrated by the case of a flagpole and its shadow. The covering law approach gives an explanation of the length of the shadow from knowledge of the height of the flagpole and the position of the sun, but it also supports an argument that the length of the shadow explains the height of the flagpole (and the position of the sun), which is rather an unsatisfying "explanation" in the common sense of the word (see Godfrey-Smith 2003).

Later attempts at providing a better base for explanations have moved away from this logical conceptualization to include the notion that explanation is a communicative process (see, for example, Achinstein 1983). This second communicative school of thought argues that it is important for explanations to include notions of causality that do not depend on law-like generalizations or statistical association alone, but refer to other causal mechanisms including teleological-type causes. In the remainder of this essay, the terms explanation or causal explanation refer to this second wider view of explanation, rather than the narrower covering-law approach.

The different views on causality and explanation are evident in different approaches to theory. On the one hand, Dubin (1978) specifically excludes causal relationships, ${ }^{5}$ stating that

Empirically relevant theory in the behavioral and social sciences is built upon an acceptance of the notion of relationship rather than the notion of causality (p. 96).

\footnotetext{
${ }^{5}$ It is somewhat surprising to find these views in the latter part of Dubin's text. In an early chapter, Dubin describes clearly how a theory can contain propositions of two types (Dubin 1978, pp. 30-31): one for prediction of outcomes and one for describing processes. He sees causal process-type statements as useful in a chain of statements, to link and justify the outcome-type statements. However, he does not follow through with this view when specifying the components of theory, where he excludes process-type causal explanation. It is possible that a number of researchers who use Dubin as a reference do not agree with his view on the omission of causality from theory, or are not aware that it is a part of his arguments.
}

Dubin assigns reasoning about causality in theory to "rhetoric" (p. 96) and rests his arguments in part on views expressed by an early $20^{\text {th }}$ century physicist and philosopher of science, Pierre Duhem, who also held

A physical theory is not an explanation. It is a system of mathematical propositions, deduced from a small number of principles, which aim to represent as simply, as completely, and exactly as possible a set of experimental laws (Duhem 1962, p. 7).

Other philosophers of science offer a contrasting view of the role of explanations in theory. Nagel (1979) distinguishes theories from experimental laws, believing that theories are more comprehensive, whereas an experimental law can be a single statement. A theory is a system of interrelated statements, possibly containing abstract theoretical terms that cannot be translated into empirical measures. The theory might also include statements about causality, with varying concepts of causality, including teleological causation, so that the theory provides causal explanations.

Apart from explanations, theories can also aim at predictions, which allow the theory both to be tested and to be used to guide action. Prediction goes hand in hand with testing. For example, we can make a prediction "If a systems test is not carried out, then a system will fail." This proposition can both be tested against what happens in practice with projects, and also used to guide action, if it is believed to be accurate.

Some theories can focus on one goal, either explanation or prediction, at the expense of the other. That is, it is possible to achieve precise predictions without necessarily having understanding of the reasons why outcomes occur. Using an everyday example, it is possible to predict from the appearance of clouds that it about to rain, without having an understanding of how precipitation occurs. Moreover, it is possible to have models that are powerful in contributing to understanding of processes without providing, at the same time, precision in prediction. Case studies of information systems implementation might give us a good understanding of how lack of involvement of users can lead to user dissatisfaction with a completed system. It would still be difficult to predict with any degree of accuracy the degree of user dissatisfaction arising from lack of involvement over a wide range of systems and settings. Dubin refers to these situations as the precision paradox and the power paradox respectively.

The distinction between the goals of explanation and prediction is central to the differentiation among types of theory in the taxonomy proposed in this paper. 


\section{Classifying Theory in} Information Systems

A central question for this essay is how to construct a classificatory scheme for theories in Information Systems. McKelvey (1982) reviews a number of methods that have been proposed for the construction of taxonomies and illustrates his arguments in the context of organizational classification. This branch of enquiry is referred to as systematics (Simpson 1961) and dates back to the logical enquiries of Aristotle and Plato and their study of the hidden nature or form or essence of things. A difference between the illustrations of classificatory schema given by McKelvey and the objects of enquiry in this essay is that the former concerns the objects of natural and social science, such as organizations, plants, and animals, while the concern in this essay is with the structural nature of theories, which are abstract entities. The classification system proposed resulted from an iterative process involving the study of the nature of theories evident in IS, analysis of prior work, and refinement of an analytic classification method that distinguished among the classes of theory on the basis of their important attributes. Alternative methods would include forms of empirical classification, which could, for instance, involve the study of what forms of theory have occurred in IS publications over a period of time and allow groupings to emerge from this study on the basis of the characteristics of the theories observed, possibly using a statistical technique such as cluster analysis. An analytic method is adopted here as it is believed to be more suitable when the defining attributes of theory can be extracted from a considerable literature.

The advantage gained by classifying objects of interest in a taxonomy is that like properties of a class of phenomena can be identified and a means is provided for comparing and contrasting classes. Identification of which class a proposed piece of work falls into provides some guidelines as to how the theory developed should look and how it can be evaluated. The criteria for evaluating classification schema and taxonomies should be considered (see Doty and Glick 1994). These theories (of Type I in the taxonomy) are expected to be complete and exhaustive; that is, they should include classes that encompass all phenomena of interest. There should be decision rules, which hopefully are simple and parsimonious, to assign instances to classes and the classes should be mutually exclusive. In addition, as taxonomies are proposed to aid human understanding, we would like the classes to be easily understood and to appear natural.

The method for classifying theory for IS proposed here begins with the primary goals ${ }^{6}$ of the theory. Research begins with a problem that is to be solved or some question of interest. The theory that is developed should depend on the nature of this problem and the questions that are addressed. Whether the questions themselves are worth asking should be considered against the state of knowledge in the area at the time. The four primary goals of theory discerned are

- Analysis and description. The theory provides a description of the phenomena of interest, analysis of relationships among those constructs, the degree of generalizability in constructs and relationships and the boundaries within which relationships, and observations hold.

- Explanation. The theory provides an explanation of how, why, and when things happened, relying on varying views of causality and methods for argumentation. This explanation will usually be intended to promote greater understanding or insights by others into the phenomena of interest.

- Prediction. The theory states what will happen in the future if certain preconditions hold. The degree of certainty in the prediction is expected to be only approximate or probabilistic in IS.

- Prescription. A special case of prediction exists where the theory provides a description of the method or structure or both for the construction of an artifact (akin to a recipe). The provision of the recipe implies that the recipe, if acted upon, will cause an artifact of a certain type to come into being.

Combinations of these goals lead to the five types of theory shown in the left-hand column of Table 2. The distinguishing features of each theory type are shown in the right-hand column. It should be noted that the decision to allocate a theory to one class might not be straightforward. A theory that is primarily analytic, describing a classification system, can have implications of causality. For example, a framework that classifies the important factors in information systems development can imply that these factors are causally connected with successful systems development. Some judgement may be needed to determine what the primary goals of a theory are and to which theory type it belongs.

\footnotetext{
${ }^{6} \mathrm{~A}$ theory is an artifact in that it is something that would not exist in the real world without human intervention. The word goal here means the goal of the artifact in the sense that it is the causa finalis, the final cause or end of the artifact (following Aristotle's writing on the four explanations of any "thing" in The Four Causes, from a translation by Hooker 1993). The goal of a theory is "what the theory is for": analyzing, explaining, predicting, or prescribing. For a more commonplace artifact such as a table, the causa finalis is what the table is for (e.g., eating from).
} 
Table 2. A Taxonomy of Theory Types in Information Systems Research

\begin{tabular}{|c|c|}
\hline Theory Type & Distinguishing Attributes \\
\hline I. Analysis & $\begin{array}{l}\text { Says what is. } \\
\text { The theory does not extend beyond analysis and description. No causal relationships among } \\
\text { phenomena are specified and no predictions are made. }\end{array}$ \\
\hline II. Explanation & $\begin{array}{l}\text { Says what is, how, why, when, and where. } \\
\text { The theory provides explanations but does not aim to predict with any precision. There are no } \\
\text { testable propositions. }\end{array}$ \\
\hline III. Prediction & $\begin{array}{l}\text { Says what is and what will be. } \\
\text { The theory provides predictions and has testable propositions but does not have well-developed } \\
\text { justificatory causal explanations. }\end{array}$ \\
\hline $\begin{array}{l}\text { IV. Explanation and } \\
\text { prediction (EP) }\end{array}$ & $\begin{array}{l}\text { Says what is, how, why, when, where, and what will be. } \\
\text { Provides predictions and has both testable propositions and causal explanations. }\end{array}$ \\
\hline Design and action & $\begin{array}{l}\text { Says how to do something. } \\
\text { The theory gives explicit prescriptions (e.g., methods, techniques, principles of form and function) } \\
\text { for constructing an artifact. }\end{array}$ \\
\hline
\end{tabular}

\begin{tabular}{|c|c|}
\hline $\begin{array}{l}\text { Theory Component } \\
\text { (Components Common to All Theory) }\end{array}$ & Definition \\
\hline Means of representation & $\begin{array}{l}\text { The theory must be represented physically in some way: in words, mathematica } \\
\text { terms, symbolic logic, diagrams, tables or graphically. Additional aids for repre- } \\
\text { sentation could include pictures, models, or prototype systems. }\end{array}$ \\
\hline Constructs & $\begin{array}{l}\text { These refer to the phenomena of interest in the theory (Dubin's "units"). All of the } \\
\text { primary constructs in the theory should be well defined. Many different types of } \\
\text { constructs are possible: for example, observational (real) terms, theoretical } \\
\text { (nominal) terms and collective terms. }{ }^{*}\end{array}$ \\
\hline Statements of relationship & $\begin{array}{l}\text { These show relationships among the constructs. Again, these may be of many } \\
\text { types: associative, compositional, unidirectional, bidirectional, conditional, or } \\
\text { causal. The nature of the relationship specified depends on the purpose of the } \\
\text { theory. Very simple relationships can be specified: for example, " } x \text { is a member of } \\
\text { class A." }\end{array}$ \\
\hline Scope & $\begin{array}{l}\text { The scope is specified by the degree of generality of the statements of relationships } \\
\text { (signified by modal qualifiers such as "some," "many," "all," and "never") and } \\
\text { statements of boundaries showing the limits of generalizations. }\end{array}$ \\
\hline $\begin{array}{l}\text { Theory Component (Components } \\
\text { Contingent on Theory Purpose) }\end{array}$ & Definition \\
\hline Causal explanations & $\begin{array}{l}\text { The theory gives statements of relationships among phenomena that show causa } \\
\text { reasoning (not covering law or probabilistic reasoning alone). }\end{array}$ \\
\hline Testable propositions (hypotheses) & $\begin{array}{l}\text { Statements of relationships between constructs are stated in such a form that they } \\
\text { can be tested empirically. }\end{array}$ \\
\hline Prescriptive statements & $\begin{array}{l}\text { Statements in the theory specify how people can accomplish something in practice } \\
\text { (e.g., construct an artifact or develop a strategy). }\end{array}$ \\
\hline
\end{tabular}

*Dubin (1978) defines a real unit as one for which an empirical indicator can be found, and a nominal unit as one for which an empirical indicator cannot be found. Collective units are a class or set of units while member units are the members of the class or set. Further distinctions are made between enumerative, associative, relational, statistical, and complex units. 
Table 3 shows the components of theories across the taxonomy. This specification allows IS researchers (1) to identify what theory is composed of in general and (2) to analyze the components of their own theory and the theory of others. This framework is used in the following section for the analysis of examples of theories.

Some components of theory are necessary for other components. Each theory must have some means of representation. ${ }^{7}$ The focus in this paper is on the structural analysis of theory that is accessible to more than one person, that is, it can be communicated. Thus, the means of representation for theory include words, either spoken or written, mathematical symbols, operators from symbolic logic, diagrams, graphs, and other pictorial devices. It is possible that working models or prototypes could also be used to represent constructs or relationships. A single concept can have more than one physical representation: for example, the mathematical symbol "=" represents the same concept as the words "is equal to." Each theory must also have constructs, which refer to the entities that the theory concerns. These entities could be physical phenomena or abstract theoretical terms. All the other components of theory depend on these basic components.

Theoretical statements are composed of words or symbols that represent constructs (for example, $e=m c^{2}$ ). Statements of relationship, scope, explanation, prediction, and prescription are all different types of statements. The active words, or verbs, in a statement will distinguish the type of statement. Membership of a class or category is indicated by words such as "belongs to" or "is a." Words such as "led to," "influences," or "constrains" imply causality. The terms "associated with" and "linked" are frequently used but are less informative. They could mean "correlated with," "came before," "composed of," "located next to," or something else. Prescriptive statements can take an imperative form: "A system of type $\mathrm{x}$ should include functions $\mathrm{a}, \mathrm{b}$ and $\mathrm{c} . "$

The taxonomic method proposed can be compared with other taxonomies proposed for theory types on the basis of their structural character, although few systematic attempts at classifying theories across paradigms can be found. Fawcett and Downs (1986), working in the field of nursing, classified theories as descriptive, explanatory, or predictive. Their taxonomy, while being an influence on the current work, excludes prescriptive theory of the type needed for design and action and includes theory that is purely descriptive. Iivari (1983) distinguished three levels of theorizing for IS: (1) a conceptual level, at which the objects of enquiry are defined;

\footnotetext{
${ }^{7}$ This paragraph gives a very simple account of notions of representation, signs, and meaning, which are dealt with at great length elsewhere (e.g., in semiotics).
}

(2) a descriptive level, at which the explanatory conjectures and hypotheses are generated and tested; and (3) a prescriptive level, at which methods for constructing systems are put forward, with recommendations for their practical use. Iivari's views are congruent with what is proposed here, although presented with less detail and the distinctions among the levels are less fine-grained.

Cushing (1990) distinguished frameworks, descriptions of facts, empirical generalizations, and theory as separate steps in a program of scientific research. His breakdown of steps has some similarities with the classification schema proposed here, except his steps are means toward a single form of "scientific theory," rather than each step being recognized as a legitimate form of theorizing in its own right.

Markus and Robey (1988) also distinguished theory partly in structural terms, considering (1) the nature of the causal agency (technological, organizational or emergent); (2) the logical structure (whether variance or process theory); and (3) the level of analysis. The first dimension defines the adoption of a particular theoretical stance, rather than a metatheoretical dimension. The third dimension of level of analysis is related to the degree of generality of a theory. As such, it is a possible candidate for classifying theory, potentially giving a two-dimensional classificatory schema.

Markus and Robey's second dimension deserves further consideration, as there are divergent views on the nature of process-type theory and variance-type theory. In one view, variance-type theory is seen as possessing laws of interactions (relationships) such that

1. Given variation in the values of a unit (A),

2. what other units $(B, C, \ldots K)$ can be linked to the first (by laws of interactions)

2. so that the variance in values of the original unit (A) may be accounted for by the linked variations of values in the other units $(\mathrm{B}, \mathrm{C}, \ldots \mathrm{K})$ ? (Dubin 1989, p. 92).

Process theory is seen as offering

An explanation of the temporal order in which a discrete set of events occurred, based on a story or historical narrative (Huber and Van de Ven 1995, p. vii).

Some authors argue that process-theory and variance-theory should be kept separate. Mohr (1982) believed that the attempt to mix them constituted "a significant impediment, one source of the frustration of theory" (p. 37) and other writers have adopted this view (for example, Seddon 1997). 
It is important to realize that Mohr presents some controversial views, equating variance theory with the laws of nature-yet, as seen earlier, a number of philosophers, going back to Hume, have argued that the degree of regularity found in the laws of nature should not be adopted or sought in the social sciences (see Little 1999). Further, Mohr argues that variance theory has explanations of causality reliant on the identification of sufficient and necessary antecedent conditions for an outcome. This view of causation presents a number of difficulties, including that of the asymmetry of causation as discussed under the covering-law model of explanation, and also the problem that the identification of necessary and sufficient conditions is considered unlikely in "open" systems such as social systems, compared with the relatively "closed" systems found in the experimental sciences. An alternative view sees process and variance theorizing (as defined by Dubin rather than Mohr) as interrelated, with both necessary for developing satisfying and sound theory and arguing for causality in different ways. Research might carry out process-type case studies of the context, content, and settings in which information systems are introduced and isolate some of the more important conditions and events that lead to various outcomes. Variance-type studies could further investigate the degree of the relationships among the identified events, conditions and outcomes using statistical techniques and larger samples (for a fuller explanation of this view, see Huber and Van de Ven 1995). ${ }^{8}$

Lee, Barua and Whinston (1997) discussed theory in IS in terms of underlying causal relationships, but primarily from a statistical viewpoint, which gives a narrower focus than that of this essay.

The current taxonomy builds on the prior work on the structural nature of theory in IS. It is regarded as an advance, however, as it offers a fuller and more systematic basis for classifying theory.

Note that some further distinctions among theories in the literature do not depend on the structural nature of the theory. Rather, different theory types are distinguished depending on their association with particular epistemological positions or with particular socio-political aims. The distinctions made concern the third and fourth classes of questions distinguished in the introduction rather than the second. Thus, we find theories identified by their origin or research method; for example, grounded theory refers to theory that emerges from the grounded theory method, which involves close and careful

\footnotetext{
${ }^{8}$ The view that process and variance explanations can coexist in one theory does not mean that it is a simple matter to draw a box-diagram model representing the theory as a whole, or that both process and variance components can easily be tested in a single study (see also the views of DeLone and McLean (2003) in their re-specification of their success model).
}

analysis of data (Glaser and Strauss 1967). Similarly, theory can be referred to as deductive, meaning that it has been deduced from an existing body of theory, or inductive, meaning that it is derived from data.

Critical theory seeks to bring about improvements in the lives of human actors. Theory labeled normative has an ethical or moral dimension in addressing what should be done. Normative theory differs from theory for design and action (Type V) in that the latter does not imply that one course of action is better than another in a moral or ethical sense. Again, all of the theory types depicted here could have social or political implications. The mere act of classifying people or things into groups and giving them names ("black" versus "white") can give rise to stereotypical thinking and have political and social consequences (see Foucault 1971). However, while attributes of theory that relate to epistemological and socio-political questions are very real and important, they are beyond the scope of the current work, which focuses on the structural aspects of theory.

The following sections describe the five different types of theory that are identified as germane to IS.

\section{Five Types of Theory in Information Systems}

A detailed description of each type of theory follows, with examples as illustrations. There is some variation within each theory type, with different types of work depending on the focus of work undertaken and the scope of the theory. The examples given for each theory type are analyzed for evidence of all seven theory components identified earlier: means of representation, constructs, relationships, scope, causal explanations, falsifiable statements, and prescriptive statements. This analysis of existing work is not straightforward, as theories are rarely presented explicitly in terms of these seven components and some interpretive licence has been employed in presenting the examples. In addition, as noted earlier, the classification is dependent on the main or primary goals of the theory, rather than goals that are present only to a minor degree. For example, a theory that focused primarily on prediction yet had some explanations of a very rudimentary type would be classified as Type III.

\section{Type I: Theory for Analyzing}

Analytic theories analyze "what is" as opposed to explaining causality or attempting predictive generalizations. These theories are 
Table 4 An Example of a Taxonomic Theory

Theory Overview

livari, Hirschheim and Klein (2000-2001) propose a dynamic framework for classifying IS development approaches and methodologies. The framework is intended to serve as an organizing and simplifying device that contributes to methodology comparisons by pointing out similarities and differences between them.

\begin{tabular}{|l|l|}
\hline Theory Component & Instantiation \\
\hline Means of representation & Words, diagrams, tables. \\
\hline Primary constructs & Paradigms, approaches, methodologies, and techniques. \\
\hline Statements of relationship & $\begin{array}{l}\text { The four tiers of the framework are comprised of paradigms, approaches, } \\
\text { methodologies, and techniques. Entities at one level are represented as inheriting } \\
\text { the features of the class to which they belong at the next level of abstraction in the } \\
\text { framework, allowing the recognition and modeling of genealogical dependencies of } \\
\text { methodologies. }\end{array}$ \\
\hline Scope & $\begin{array}{l}\text { Methodologies that have been proposed in the scholarly literature. A procedure for } \\
\text { including new methodologies as they arise is proposed. }\end{array}$ \\
\hline Causal Explanations & Not present. \\
\hline Testable propositions & Not present. \\
\hline Prescriptive statements & Not present. \\
\hline
\end{tabular}

the most basic type of theory. They describe or classify specific dimensions or characteristics of individuals, groups, situations, or events by summarizing the commonalities found in discrete observations. They state "what is." Descriptive theories are needed when nothing or very little is known about the phenomenon in question (Fawcett and Downs 1986, p. 4).

Fawcett and Downs referred to these theories as descriptive, but this term is not entirely appropriate as this class of theories goes beyond basic description in analyzing or summarizing salient attributes of phenomena and relationships among phenomena. The relationships specified are classificatory, compositional, or associative, not explicitly causal.

Variants of this theory type are referred to as classification schema, frameworks, or taxonomies. McKelvey (1982) gives a comprehensive coverage of the subject of taxonomies and classification for organizations under the heading of systematics, drawing upon work in biology, zoology, and botany, where the challenges for systematics are immense. He sees this kind of science as "the science of diversity" (p. 12). McKelvey points out the importance of systematics as a prerequisite to good scientific method, in providing clear delineation of the uniformities of classes of phenomena to be studied.
The term typology is used more or less synonymously for taxonomy and classifications, although Doty and Glick (1994) argue that its use should be restricted to the special case where there is a conceptually derived interrelated sets of ideal types. They argue that these typologies are intended to predict variance in dependent variables, because for organizations, the types identified are developed with respect to a specified organizational outcome. In this case, as the ideal types are developed with the intention of explaining or predicting outcomes through falsifiable relationships, the Doty and Glick typology is an example of theory Type III or IV in the taxonomy.

Frameworks, classification schema, and taxonomies are numerous in IS. A classic early case is Gorry and Scott Morton's (1971) framework for management information systems. Table 4 gives a more recent example. Other examples of theorizing in this category include research on the delineation of constructs and their associated measures. For example, Davis' work on defining and measuring easeof-use and usefulness analyzed the properties that defined these constructs and allowed them to be measured (Davis 1989). Some examples of grounded theory can also be examples of Type I theory, where the grounded theory method gives rise to a description of categories of interest. 
What constitutes a contribution to knowledge with theory of this type? Theory that describes and analyses is valuable, as stated above, when little is known about some phenomena. Any evidence gathered would be expected to have credibility. Descriptions presented should correspond as far as possible to "what is" (Miles and Huberman 1994).

Further evaluation depends on the subtype of the theory. The evaluative criteria for classification schema have been mentioned before. If any classification system is developed, implicit claims are that the classification system is useful in aiding analysis in some way, that the category labels and groupings are meaningful and natural, ${ }^{9}$ and that hierarchies of classification are appropriate (most important divisions are shown at the highest level). The logic for the placement of phenomena into categories should be clear, as should the characteristics that define each category. In addition, important categories or elements should not be omitted from the classification system, that is, it should be complete and exhaustive. A previous classification system could be revised as new entities come to light, or some preferable way of grouping or naming categories is identified. A judgement as to the degree to which the theory satisfies these criteria allows one to assess the contribution to knowledge.

\section{Type II: Theory for Explaining}

This type of theory explains primarily how and why some phenomena occur. These theories are formulated in such a way, however, that making testable predictions about the future is not of primary concern. Explanations of how, when, where, and why events occurred may be presented, giving rise to process-type theory. This class could well be labeled theory for understanding, as these theories often have an emphasis on showing others how the world may be viewed in a certain way, with the aim of bringing about an altered understanding of how things are or why they are as they are.

At least two subtypes of work may be distinguished here. In the first, theory is used as a "sensitizing device" at a high level to view the world in a certain way (Klein and Myers 1999, p. 75). DiMaggio (1995, p. 391) describes theory as enlightenment, where theory serves as

\footnotetext{
${ }^{9}$ Foucault (1971, p. xv, citing Borges) gives a striking example of a taxonomy that violates our innate sense of order. A "certain Chinese encyclopedia" is reputed to have written that "animals are divided into: (a) belonging to the Emperor, (b) embalmed, (c) tame, (d) sucking pigs, (e) sirens, (f) fabulous, (g) stray dogs, (h) included in the present classification, (i) frenzied, (j) innumerable, (k) drawn with a very fine camel-hair brush, (l) et cetera, (m) having just broken the water pitcher, (n) that from a long way off look like flies."
}

A device of sudden enlightenment. From this perspective theory is complex, defamilarizing, rich in paradox. Theorists enlighten not through conceptual clarity... but by startling the reader into satori. The point of theory, in this view, is not to generalize, because many generalizations are widely known and rather dull. Instead, theory is a "surprise machine"...a set of categories and domain assumptions aimed at clearing away conventional notions to make room for artful and exciting insights.

High-level Type II theories include structuration theory, an understanding of the world as reciprocal relationships between action and social structure (Giddens 1984), actornetwork theory, an understanding of inanimate objects and material systems as actors or co-agents of human intentional actors (Latour 1991) and the situated-action perspective, a model that contrasts routine activity situated in an environment with theories of deliberative action (Agre 1995).

In a second subtype of theory for explaining at a lower level, explanations are given for how and why things happened in some particular real-world situation. Many case studies fall into this category. A nice example from history could be a case study of Napoleon's march on Moscow. Such a case study could analyze the causal factors that contributed to a military defeat (such as campaigning in winter without good supply lines). Similarly, case studies of failure in IS can give a good understanding of what not to do when building systems. For example, an analysis of three case studies of fairly catastrophic IS failures showed that, in all cases, there had been a lack of managerial attention to recognized IT governance and project management principles (Avison et al. 2006).

It can be seen that forms of this type of theory correspond reasonably closely to some views of theory in the interpretivist paradigm (Klein and Myers 1999), although other interpretive theory is framed in such a way that it includes testable propositions, making it possibly Type IV. Table 5 shows an example of theory for explaining in IS that fits the interpretivist paradigm, where the theory itself is an end product and is not expected to lead to predictive, deterministic theory.

Research approaches that can be used to develop this type of theory include case studies (Yin 1994), surveys, ethnographic, phenomenological, and hermeneutic approaches (Denzin and Lincoln 1994), and interpretive field studies (Klein and Myers 1999). 
Table 5 Example of Theory for Explaining

Theory Overview

Orlikowski (1992) developed a new theoretical model, the structurational model of technology, which made the claim that technology is both constituted by human agency and constitutes human practice.

\begin{tabular}{|l|l|}
\hline Theory Component & Instantiation \\
\hline Means of representation & Words, diagrams, tables. \\
\hline Primary constructs & $\begin{array}{c}\text { Technology, with various conceptions in terms of both its scope and role. Structural features } \\
\text { of organization, including rules and resources. }\end{array}$ \\
\hline Statements of relationship & $\begin{array}{c}\text { An example: } \\
\text { Technology is an outcome of such human action as design, development, } \\
\text { appropriation, and modification (p. 410). }\end{array}$ \\
\hline Scope & $\begin{array}{l}\text { The statements of relationships include no modal qualifiers. A very high level of generality } \\
\text { is suggested. No boundaries to the theory are stated. }\end{array}$ \\
\hline Causal Explanations & $\begin{array}{l}\text { The statements of relationship include causal explanations, for example: } \\
\text { interpretative schemes, facilities and norms (p. 410). }\end{array}$ \\
\hline Testable propositions & Not present. It is stated (p. 423) that the model should not be applied deterministically. \\
\hline Prescriptive statements & \begin{tabular}{l} 
Not present. \\
\hline
\end{tabular} \\
\hline
\end{tabular}

What constitutes a contribution to knowledge with theory of this type? The theory developed, or the conjectures, need to be new and interesting, or to explain something that was poorly or imperfectly understood beforehand. With case studies, more than just a "story" is expected, as to qualify as theorizing the exercise must lead to conclusions with some generality. Klein and Myers $(1999$, p. 75$)$ argue that with interpretive field studies there is a philosophical basis for abstraction and generalization:

Unique instances can be related to ideas and concepts that apply to multiple situations. Nevertheless, it is important that theoretical abstractions and generalizations should be carefully related to the field study details as they were experienced and/or collected by the researcher.

Again, we expect plausibility and credibility of any accounts given of events in the real world and justification for generalization. An aim of this type of theory is to explain how and why events happened as they did; therefore, we expect any ascriptions of causality to be made very carefully. The identification of a cause is subject to the same set of difficulties as with other research approaches. Possible alternative explanations as to what caused a particular outcome should be examined and assessed (internal validity).
Judgment regarding the contribution to knowledge for this type of theory is made primarily on the basis of whether new or interesting insights are provided, and also on the basis of plausibility, credibility, consistency, and transferability of the arguments made.

\section{Type III: Theory for Predicting}

Theories aiming at prediction say what will be but not why; parts of the system remain a "black box." These theories are able to predict outcomes from a set of explanatory factors, without explaining the underlying causal connections between the dependent and independent variables in any detail. There are several reasons for leaving part of the system a black box. First, the focus of the theoretical model could be on prediction, because that is the theorist's primary interest and detailed explanation of lower-level supporting mechanisms are thought unnecessary. Some economists admit that they are not so concerned if the assumptions underlying their theory are implausible, so long as they get high predictive power (Friedman 1953). Second, reasons to justify the ascription of causality in regularity relationships might not yet have been uncovered. Captain Cook theorized to good practical effect that regular intakes of citrus fruits helped prevent scurvy, without knowing exactly why this was so. Others 
would use the labels empirical generalizations (Cushing 1990; Kaplan 1964) or experimental laws (Nagel 1979) for this category rather than theory. Third, a leaning toward this type of theory can be detected in the logical positivist view that theory should not include statements of causality (explanations) (Dubin 1978; Duhem 1962).

Examples of this type of theory in IS do not come readily to hand, suggesting that they are not common. One example that is related to IS is Moore's Law. In 1965, Gordon Moore of Intel suggested that the number of transistors, and thus the power, of an integrated circuit would double every two years, while the cost remained the same. Moore later revised this estimate to a doubling every 18 months. Table 6 presents this example. Further examples are the algorithmic approaches to software cost estimation, including the COCOMO model, where the cost model is developed from empirical observation. Many of the mathematical formulae included have an exponential component, as experience has shown that costs do not normally increase linearly with size (Sommerville 2001). Examples are more common in finance and econometric studies, where the researcher appears to choose independent variables because they increase the $R^{2}$ in a regression analysis, rather than for any other reason. Hitt and Brynjolfsson (1996, p. 138) in developing models of value creation from IT note that they improved the fit of the models by "adding commonly used control variables." A further example provides elaboration. Organizational size is used to predict organizational innovativeness, this variable having consistently been found to be positively related to innovativeness (Rogers 1995). However, many studies offer little or no supportive analysis or justification of their use of organizational size as a predictor variable; that is, they give no causal explanation for its inclusion. Organizational size could be a surrogate for several dimensions that lead to innovation, including organizational resources, organization levels and economies of scale (Goode 2002).

Associated research approaches include statistical techniques such as correlational or regression analysis and data mining. Correlational work can be longitudinal; that is, we can show how $\mathrm{Y}$ varies with a number of independent variables $\left(\mathrm{X}_{1}\right.$, $\mathrm{X}_{2}, \ldots$ ) over a time period. Correlation studies can also be multidirectional; that is we can say larger values of $X$ are related to larger values of $Y$, and also larger values of $Y$ are related to larger values of $X$ (as in height and weight of the population). Neural net techniques allow models to be constructed that give an accurate prediction of outcomes from input variables, although the reasons for the weightings applied to input values are not transparent.

What constitutes a contribution to knowledge with theory of this type? The discovery of regularities that allow prediction can be of interest if these were unknown before, especially if the theory's predictive power is of considerable practical importance, as in the prediction of share prices in finance and in predicting the weather. The methods used to develop and test this theory are primarily quantitative, so rigor is expected in statistical design and methods.

The limitations of this type of theory should be recognized. The existence of regularities or correlations between two variables does not necessarily imply a causal relationship. Height and weight are related but one does not cause the other. The number of ice creams sold at beaches has a strong positive relationship with the frequency of shark attacks. We would not conclude that ice cream eating caused shark attacks. In both cases, a third variable, which is a determinant of both, is of more interest. This variable is temperature, with higher temperatures leading to more people at beaches and more people in the water where they can be attacked by sharks.

In addition, our practice can improve if we understand why two variables are related. Use of a proxy such as organizational size, although it may have high predictive power in many circumstances, can lead to inconsistent results (Goode 2001). From a pragmatic viewpoint, we are interested in which variables can be manipulated to bring about an outcome, so we need to know where causal relationships exist. Organizational size could be less easy to manipulate than organizational resources, which may be the "real" precondition for innovation.

\section{Type IV: Theory for Explaining and Predicting (EP Theory)}

This type of theory says what is, how, why, when, and what will be, and corresponds to commonly held views of theory in both the natural and social sciences, (although Type III theory is thought to be the natural-science type model by others). It is difficult to find an appropriate short label for this theory class without resorting to nomenclature such as "scientifictype" theory, which is not appropriate because of the conflicting views within the philosophy of science. Thus, this class will be referred to as EP theory. EP theory implies both understanding of underlying causes and prediction, as well as description of theoretical constructs and the relationships among them.

Type IV theories include "grand theories" such as general system theory (Ashby 1956; von Bertanlanffy 1973) and the related information theory of Shannon (1948). General system theory provides a very high-level way of thinking about many of the open systems of interest in IS. Open sys- 
Table 6. Example of Theory for Predicting

Theory Overview

Moore's law (1965) proposed that as technology evolved, larger and larger circuit functions could be crammed onto a single semiconductor substrate, meaning costs would continue to fall.

\begin{tabular}{|l|l|}
\hline Theory Component & Instantiation \\
\hline Means of representation & Words, graph. \\
\hline Primary constructs & $\begin{array}{l}\text { Semiconductor integrated circuits, silicone base materials, cost per component in a } \\
\text { circuit. }\end{array}$ \\
\hline Statements of relationships & $\begin{array}{l}\text { The complexity (number of components per integrated circuit) for minimum component } \\
\text { cost will increase at a rate of roughly a factor of two per year. }\end{array}$ \\
\hline Scope & $\begin{array}{l}\text { Stated as a general law using the modal qualifier "roughly" for the rate of increase. } \\
\text { Assumed that silicone was likely to remain the base material for the semiconductor } \\
\text { circuits. Expected that the relationship would hold for about 10 years. }\end{array}$ \\
\hline Causal Explanations & $\begin{array}{l}\text { The general nature of the relationship between improved technology and lower costs is } \\
\text { explained, but there is no causal explanation as to why the power doubles. This factor } \\
\text { was determined empirically by plotting the graph of the log of the number of components } \\
\text { per integrated function against the year from 1959 to 1965. }\end{array}$ \\
\hline Testable propositions & Yes. The predicted relationship could be tested. \\
\hline Prescriptive statements & Not present. \\
\hline
\end{tabular}

\section{Table 7 Example of a Theory for Explaining and Predicting}

\section{Theory Overview}

Bhattacherjee and Premkumar (2004) proposed a theory that shows the causative drivers and emergent mechanisms driving temporal changes in user beliefs and attitude toward IT usage. This theory builds on expectation-disconfirmation theory and the technology acceptance model.

\begin{tabular}{|c|c|}
\hline Theory Component & Instantiation \\
\hline Means of representation & Words, diagrams. \\
\hline Primary constructs & Antecedent conditions, beliefs, attitude, disconfirmation, satisfaction, intentions \\
\hline Statements of relationships & $\begin{array}{l}\text { An example: } \\
\text { Perceived usefulness and attitude in a pre-usage stage are linked with those in } \\
\text { the usage stage. }\end{array}$ \\
\hline Scope & $\begin{array}{l}\text { The theoretical model is given in a very general form; boundaries are not stated and the } \\
\text { hypotheses have no modal qualifiers. In testing, only one usage-related belief (perceived } \\
\text { usefulness) was examined, student subjects were used and the technologies examined } \\
\text { were computer-based training and rapid application development software. }\end{array}$ \\
\hline Causal Explanations & $\begin{array}{l}\text { Yes. See p. 234: } \\
\text { We hypothesize usage-stage belief as the joint outcome of pre-usage belief and } \\
\text { disconfirmation, and usage-stage attitude as being determined jointly by pre- } \\
\text { usage attitude and satisfaction. }\end{array}$ \\
\hline Testable propositions & Yes. The theory was tested through statistical methods and with qualitative data. \\
\hline Prescriptive statements & Not the main thrust, although recommendations for practice are given. \\
\hline
\end{tabular}


tems are seen as being in a continuous state of exchange with their environment and interacting with other systems outside of themselves. They are modeled in terms of the familiar concepts of input, throughput, output, feedback, boundary, and environment. General system theory provides testable propositions, such as the law of requisite variety: only variety in a system's responses can keep down variety in outcomes when the system is subjected to a set of disturbances (Ashby 1956). Ashby gives very detailed explanations as to why this law applies to many systems. General system theory has commonalities with other high-level approaches to theory include cybernetics, the soft systems approach, and complex systems.

Further examples of type IV theory can be distinguished. The Technology Acceptance Model (TAM) (Davis et al. 1989) and DeLone and McLean's dynamic model of information success (1992 2003) both aim to explain and predict. Weber (1997) gives a theory of representation, which aims to model the desirable properties of information systems at a deep level and be a theory native to IS.

Doty and Glick (1994) show how typologies can be another form of Type IV theory, citing the example of Miles and Snow (1978), who describe the prospector, analyzer and defender types as ideal types of organization that are maximally effective. Organizations that resemble more closely any one of the ideal types are predicted to be more effective. Table 7 gives a further example of EP theory.

Investigation of how authors specify EP theory in practice proves interesting. In many cases, it appears authors have not quite made up their mind as to whether causality is allowable in a theory or not, or where it can properly be mentioned. In specifying the theory or conceptual background in a paper, it is common to give a web of interrelated definitions and causal statements that comprise the theory. Bhattacherjee and Premkumar's (2004) description of expectation-disconfirmation theory is an example, relying explicitly on causal reasoning and using words such as change and determine and mentioning a process model. These authors have research hypotheses that are also stated in causal terms. In other research articles, the language changes in specifying a research model, propositions, and hypotheses so that any hint of causality is eliminated. Instead, vague words such as associated with or linked to, rather than the stronger words influences, leads to, or determines, which are explicitly causal. In the interests of developing stronger and clearer theory of this type, the author believes researchers should make their commitment clear and couch their propositions in terms that show what they really mean: that is, use statements such as "Failure to perform a systems test can be a cause of systems failure."
Many research methods can be used to investigate aspects of the EP theory type, including case studies, surveys, archival studies, experiments, the grounded theory approach, quasiexperiments, statistical analysis, and field studies. Although the problems with terminology were noted earlier, this type of theory can have contributions from both process studies, which look at the unfolding of events over time, and variance studies, which look at the degree to which one variable can predict changes in another variable (Huber and Van de Ven 1995). Note also that with this type of theory it is legitimate to have an overall dynamic theory (with feedback loops as in general system theory), yet test hypotheses deduced from the theory in cross-sectional (variance) studies.

What constitutes a contribution to knowledge with theory of this type? Studies can usefully contribute to either theory building or theory testing. Many authors provide discussion of how "scientific" knowledge should be generated and tested (for example, Cook and Campbell 1979; Popper 1980) and a long list of potential criteria for "good theory" can be formed, including clarity, parsimony, elegance, internal consistency, agreement with evidence, absence of disconfirmation, soundness of argument, internal and external validity, and consistency with other theory.

\section{Type V: Theory for Design and Action}

This type of theory says how to do something. It is about the principles of form and function, methods, and justificatory theoretical knowledge that are used in the development of IS (Gregor 2002a; Gregor and Jones 2004; Walls et al. 1992).

There are diverging views on the status of design theory and its relationship to other types of theory. Relevant work can be found, although it is scattered and appears under different labels. Associated research has been referred to as software engineering research (Morrison and George 1995), as a constructive type of research (Iivari 1991; Iivari et al. 1998), as prototyping (Baskerville and Wood-Harper 1998), as a systems development approach (Burstein and Gregor 1999; Lau 1997; Nunamaker et al. 1990-91), and as design science (Hevner et al. 2004 March and Smith 1995; Simon 1996).

It is clear that work of this type occupies an important place in IS. A review by Morrison and George (1995) of three leading management IS journals showed that softwareengineering related research represented about 45 percent of the IS articles found in the 6-year period from 1986 to 1991. Of the five bodies of knowledge identified by Davis (2000) as being unique or somewhat unique to IS, two relate to what could be termed design science: IS development processes and IS development concepts. 
Design science has been given validity in IS through the work of March and Smith (1995), who developed a framework to demonstrate the relationship, activities and outputs of design and natural science research. March and Smith (1995) saw four products of design science: constructs, models, methods, and implementations. These authors, however, saw the term theory as the preserve of natural science. These ideas are further developed in Hevner et al. (2004), where the "artifact itself" is emphasized as the prime or only contribution of design science, although it is recognized that the contributions of design science can include foundational constructs, models and methods for the design science knowledge base, and evaluation methods and metrics. Still, the focus of this work is on design as an activity, rather than the problem of what a special design-type theory might look like.

In contrast, the notion of design theory has been adopted by Markus et al. (2002) in specifiying a design theory for knowledge management systems (see Table 8). Other examples of design theory include methodologies-for example, structured systems analysis methods (Gane and Sarson 1979) and Multiview (Avison and Wood-Harper 1990) - and prescriptions for building specific applications - for example, decision support systems as in Turban and Aronson (2001). Codd's (1970) theory of relational database design is a further example.

Discussion of research approaches for this theory type can be found in Burstein and Gregor (1999), Hevner et al. (2004), March and Smith (1995), and Nunamaker et al. (1990-91). Action research is seen as particularly appropriate (Baskerville and Wood-Harper 1998). In support of this view, Lau's (1997) review of action research in IS studies over a 25 year period showed that 11 of the 30 articles reviewed were categorized as "systems development," covering the areas of analysis, design, development and implementation of IS and decision support systems. The case study was the preferred method of investigation. Iivari et al. (1998) argue for the particular importance of these methods for applied disciplines, such as IS and computer science.

What constitutes a contribution to knowledge with theory of this type? March and Smith and Hevner et al. point out some conditions under which they believe a contribution to knowledge in design science has occurred. Their criteria include utility to a community of users, the novelty of the artifact, and the persuasiveness of claims that it is effective. Models and methods can be evaluated for completeness, simplicity, consistency, ease of use, and the quality of results obtained through use of the method. Simon sees "interestingness" as a valid claim.

\section{Interrelationships among Theory Types}

Figure 1 depicts graphically the interrelationships among the classes of theory. The most basic type of theory, analytic theory, is necessary for the development of all of the other types of theory. Clear definition of constructs is needed in all theory formulation. Both theory for explaining and theory for predicting can sow seeds for the development of EP theory that encompasses both explanation and prediction. Design theory can be informed by all the other classes of theory. A design methodology can build on particular idiographic studies of what has worked in practice, on predictive relationships that are known but not fully understood (such as the relationship between organizational size and innovativeness), and on fully developed EP theories such as those relating to data representation or human behavior.

Design theory and EP theory are strongly interrelated. Knowledge of people and information technology capabilities informs the design and development of new information system artifacts. These artifacts can then be studied in terms of EP theory: what impacts do the artifacts have in the workplace and in society. Note that there are many examples in the history of science of the interaction between scientific knowledge and technologies. The invention of the telescope allowed Galileo to make astronomical observations and confirm predictions made from theory about the phases of Venus (Gribbin 2002). Yet, a design theory for a telescope relies on knowledge of optics for its design principles.

Some broad bodies of theory include all classes of theory and are perhaps most likely to be found in monographs. An example is the work on electronic markets by Ajit Kambil and Eric van Heck and their colleagues at Erasmus University in Rotterdam, which is described in a series of research articles and the monograph Making Markets (Kambil and van Heck 2002). This body of theory includes Type I theory. A framework was developed showing 11 key market processes that are related to the execution of trading of any kind (pp. 26-28). Key insights that "resonate time and again throughout the book" are Type II theory, for example, "Electronic markets are not technological interactions supported by humans. They are human interactions supported by technology" (p. 3). Further Type II theory is represented by the insights from the numerous case studies included. A study by Jochem Paarleburg is an example of Type III theory (p. 69). This study examined 194 consumer Web auctions in 8 countries and developed an index for the maturity of each in terms of trade processes. Statistical analysis showed that auctions with a higher level of maturity had a higher transaction volume. The authors note this correlation, but do not attribute causality. 
Table 8 Example of a Theory for Design and Action

Theory Overview

Markus et al. (2002) proposed a design theory for systems that support emergent knowledge processes.

\begin{tabular}{|l|l|}
\hline Theory Component & Instantiation \\
\hline Means of representation & Words, tables, screen shots, diagrams. \\
\hline Primary constructs & $\begin{array}{l}\text { Users, work context, information requirements, system architecture, system processes (and } \\
\text { more). }\end{array}$ \\
\hline Statements of relationships & $\begin{array}{l}\text { An example: } \\
\text { Design for customer engagement by seeking out naïve users (p. 188), } \\
\text { that is, involvement of naïve users leads to a greater degree of customer engagement. }\end{array}$ \\
\hline Scope & Systems that support emergent knowledge processes. \\
\hline Causal Explanations & $\begin{array}{l}\text { Underlying micro or kernel theories that explain the design include an understanding of the } \\
\text { nature of emergent knowledge processes. One requirement of these processes is that } \\
\text { general expert knowledge must be contextualized when making decisions, something that } \\
\text { familiar expert systems are unlikely to supply, so that supplementation by personal } \\
\text { communication systems should be considered. }\end{array}$ \\
\hline Testable propositions & $\begin{array}{l}\text { The claim is made that the design theory will assist designers of other systems with similar } \\
\text { requirements. }\end{array}$ \\
\hline Prescriptive statements & $\begin{array}{l}\text { The design theory specifies the meta-requirements addressed by the theory and gives a set } \\
\text { of system features and a set of system principles for system development to meet these } \\
\text { requirements. The user requirements include a need to translate expert knowledge into } \\
\text { actionable knowledge for non-experts. One development principle is that knowledge } \\
\text { translation requires radical iteration with functional prototypes. }\end{array}$ \\
\hline
\end{tabular}

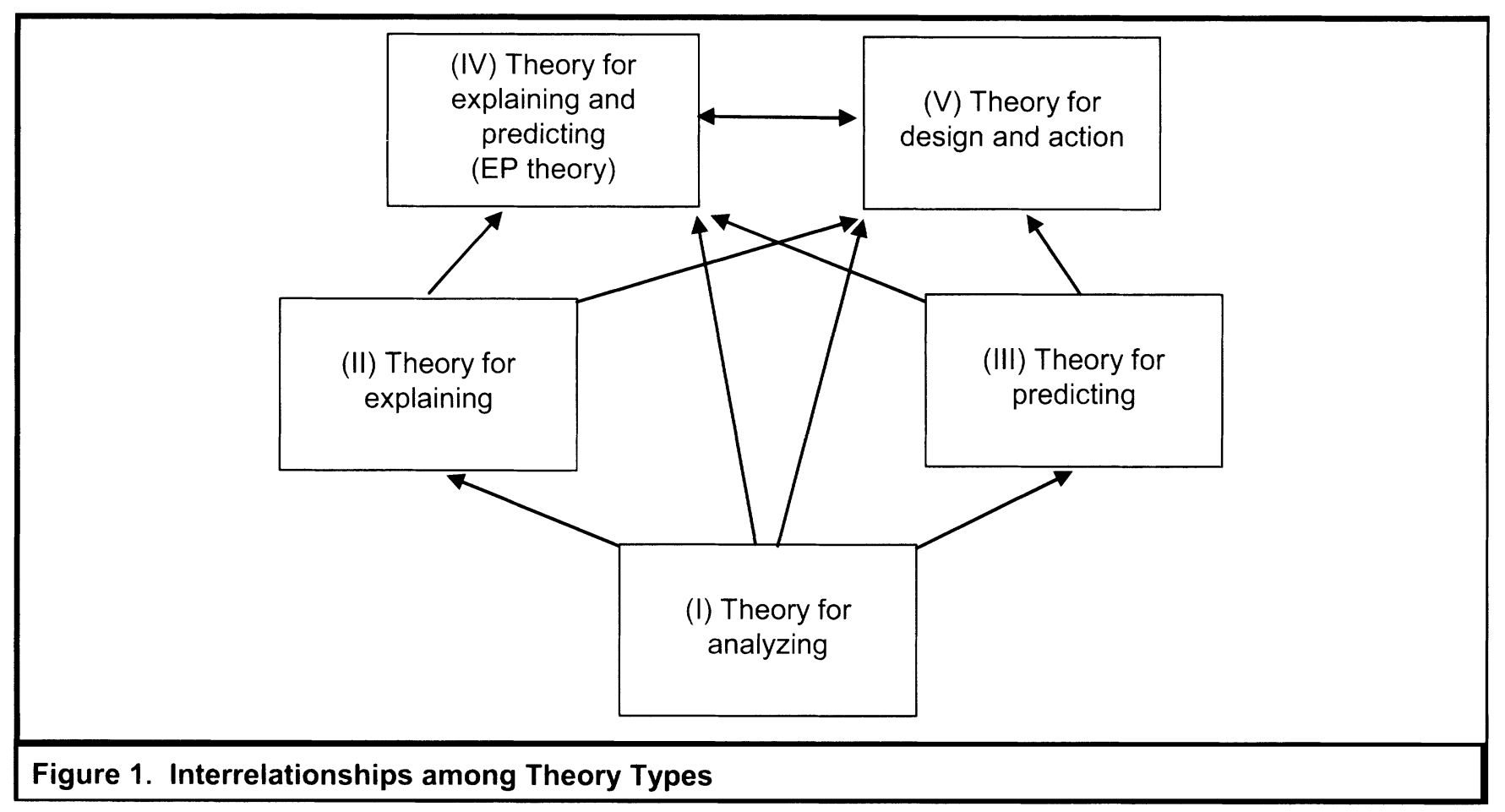


Type IV theory was tested in several ways. Experiments by Otto Koppius to test the effects of information feedback in multi-attribute reverse auctions are reported (p. 82). Type $\mathrm{V}$ theory is evident in the guidelines that are given for the construction of electronic markets: "You must also create a social context for trading, one that is similar to traditional markets" (p. 3) and the strategies for introducing dynamic markets (Chapter 8). The integration of different sources of evidence and different types of theorizing in this monograph is impressive and the book has appeal to practitioners. Personal experience has shown that it was read and appreciated by the manager of a farmers' cooperative that was in the early stages of developing an electronic market. Moreover, the underlying academic work satisfies rigorous academic standards. Koppius' (2002) thesis study was awarded the International Conference on Information Systems (ICIS) Best Dissertation Award in 2002. Together, these endeavors have led to a comprehensive, impressive body of theory.

It has been argued in other disciplines that different approaches to theory should be recognized and combined. In the field of management, DiMaggio (1995) suggests that many of the best theories are hybrids, combining the best qualities of covering-law, enlightenment, and process approaches. DiMaggio sees each of these types of theory as valid, but limited. In a similar vein, Weick (1995) sees many products that are labeled as theory as valuable, but as approximations to theory, with "strong" or "full-blown" theory a result of many interim struggles in theorizing.

\section{Application of the Taxonomy}

The taxonomy was used to classify 50 research articles in two leading journals to demonstrate its applicability. Issues of MIS Quarterly and Information Systems Research from March 2003 to June 2004 were used as the source of the articles. All articles except issues and opinions, review articles, and research essays were included in the classification process. Classification was performed by the author and a junior researcher independently, using the distinguishing attributes in Table 2 as the primary basis for decisions to assign an article to one of Types I to V. Of the 50 articles studied, 45 were classified identically by each researcher separately in the initial round. Five articles required discussion before a decision was made on classification. The appendix shows the results of this classification.

The purpose of this classification activity was not to determine the relative frequency of publication of different theory types, but to test on a small scale whether the classification schema is (1) exhaustive, (2) understandable, and (3) does not have unnecessary categories. The activity showed that the schema appears to be exhaustive: no papers were found that could not be classified under the schema. The decision rules to allocate theory to a category appear to be understandable, as the junior researcher was able to apply them independently and arrive at similar conclusions to the author. The question arises as to whether the Type III category is really necessary. Only one article was found with theory that fell into category III: prediction without causal explanation. It is believed that this category should be retained, even if instances in this class are few, both for analytic completeness and as it is a type of theory recognized by a number of authors. Table 9 shows the relative frequency of each theory type.

\section{Questions for Discussion}

This essay has presented a number of ideas about theory in IS and proposed a taxonomy for classifying the theories we develop. Many of the ideas about theory presented are not new and have been taken from a considerable literature. Nevertheless, the selection and combination of these ideas leads to a taxonomy that differs considerably in emphasis from what is commonly found in discussion of IS research. An aim of the paper is to challenge and promote discussion of the nature of theory as a topic worthy of discussion in its own right. To this end, discussion follows under the headings of questions that encourage dialectic and some personal opinions and value judgements are included.

\section{Do some theory types belong to particular research paradigms?}

An unequivocal "no" is the answer to this question. In principle, one individual could theorize using any of the forms of theory. Theory Types II to V require some form of realist ontology, as constructs in theoretical statements can refer to entities in the real world. Type I theory does not necessitate reference to real-world entities, but could be purely analytic, as in mathematics and logic. Apart from this qualification, none of the theory types necessitate a specific ontological or epistemological position (for example, an interpretative stance, or naïve realism, or value-free enquiry, or quantitative methods). While it is argued that no theory class is exclusively the province of any paradigm, proponents of specific paradigms favor some forms of theory more than others. Proponents of the interpretivist paradigm have argued for the recognition of theory Type II: theory for explaining but not precise prediction. Logical positivism, characterized as an extreme form of empiricism, can be linked to some propo- 


\section{Table 9 Classification of articles in MIS Quarterly and Information Systems Research (March 2003 - June 2004)}

\begin{tabular}{|l|c|}
\hline \multicolumn{1}{|c|}{ Theory Type } & Frequency of Occurrence \\
\hline I. Analysis & 3 \\
\hline II. Explanation & 4 \\
\hline III. Prediction & 1 \\
\hline IV. Explanation and prediction (EP) & 33 \\
\hline V. Design and action & 9 \\
\hline & Total \\
\hline
\end{tabular}

nents of theory Type III. It would be wrong to conclude, however, that all people who develop Type III theory are logical positivists or that all people who develop theory Type II are interpretivists, or that interpretivists build theory Type II only. What is commonly held to be natural-science type theory is Type III or Type IV theory, where there is theory that can be tested. It appears that people who describe themselves as positivist researchers in IS do so primarily when they engage in research that includes testable theory of these types. Again, this is not to say that only people who call themselves positivists build Types III and IV theory.

To reiterate, paradigmatic labels should not be attached to any of the theory types. There is no clear and direct connection between any theory type and any one paradigm.

\section{Is one type of theory more valuable than another?}

Here again a very strong "no" is the answer to this question. The discussion of the classes of theory has avoided as far as possible any value-laden words like formal, traditional, complete, or "higher" or "lower" theory. Each class of theory can provide important and valuable contributions.

Illustrating the importance of Type I theory, we see examples such as Linnaeus' $18^{\text {th }}$ century system for classifying plants into groups depending on the number of stamens in their flowers, which provided a much-needed framework for identification (Wordsworth 1994). The many examples in IS include Kwon and Zmud's (1987) effort to unify the fragmented models of information systems implementation with a categorization of factors linked to the implementation process. Type II theories have led to important new insights into phenomena related to IS. Type V theory also has obvious value in IS. This type of knowledge is what we impart to our students and what fills our textbooks on applications and systems development (for example, see the text by Turban and Aronson (2001) on decision support and intelligent systems).
Types III and IV theory match common conceptions of scientific-type theory, according to the natural sciences model, as they provide theory that yields testable propositions. As such, they have found ready acceptance in IS. The words scientific and science, however, are used in different ways in different quarters, so it is unwise to attach them definitively to any of the theory types or to use them to argue for the legitimacy or value of one type of theory at the expense of another.

Should the word theory be used for all five classes of theory?

Proponents have been identified for each theory type to show that each has some support as a form of theorizing. For each class, however, there are also opponents, who would not agree that this is an appropriate view of theory. Taking each class of theory in turn,

- Type I: Analytic theory. Proponents include Fawcett and Downs (1986) and McKelvey (1982). Others (Bacharach 1989; Doty and Glick 1994; Dubin 1978; Kerlinger 1973; Nagel 1979; Popper 1980) would argue against this class of theory because no predictions are made that can be empirically tested. This class also does not entail reasoning on the basis of causality of any type, which would further disqualify it from being theory for some (Nagel 1979).

- Type II: Theory for explaining. A form of theory recognized by DiMaggio (1995), Guba and Lincoln (1994), Klein and Myers (1999), and Schwandt (1994). Again, the omission of statements that can be empirically tested would disqualify this class of theory for some (Doty and Glick 1994; Dubin 1978; Kerlinger 1973; Nagel 1979; Popper 1980).

- Type III: Theory for prediction. This class matches Dubin's (1978) specification of theory, eschewing state- 
ments of causality (explanations) in theory, believing that they belong to the field of rhetoric. Friedman's (1953) views add support. Others would disagree with this view of theory, either implicitly or explicitly endorsing a view that theory should include underlying justifications for causally based explanations, not just covering-law explanations on the basis of universal or statistical regularities (Kaplan 1964; Merton 1967; Nagel 1979).

- $\quad$ Type IV: Theory for explaining and predicting. Authors who expect both explanation and prediction in a theory include Kaplan (1964), Kerlinger (1973), Merton (1967), and Nagel (1979). Some opposition to this type of theory can be detected in the work of Mohr (1982), who held that process-type and variance-type theory should not be mixed. The examination of a sample of IS articles, however, showed a majority were classified as Type IV theory.

- Type V: Theory for design and action. Simon (1996) is the well-recognized proponent of this form of theory and others have followed his lead (Gregor and Jones 2004; Iivari 1983; Markus et al. 2002; Walls et al. 1992). Otherwise there is some feeling against recognizing design principles as theory. March and Smith (1995) and Hevner at al. (2004) promote design science as a research activity, but reserve the word theory for natural-sciencetype research (Type III and IV theory).

The approach argued for here is one of comprehensiveness, where, following Weick (1995, p. 386),

We would like writers to feel free to use theory whenever they are theorizing. Modesty is all very well, but leaning over too far backward removes a good word from currency.

An advantage of labeling as theory varying forms of theory development is that it forces theorizers to think clearly about what type of knowledge they are aiming at, and the nature of the statements that can and should be made within that theory type. Another outcome of thinking of theory in this way is that individual contributions to theory can be considered as complementary and integrated development of theory facilitated. Each type of theory lacks something that another type has. Stronger and fuller theory can result if we regard our efforts in building one type of theory as part of a larger whole and remain aware of potential connections between the subparts.

\section{Could there be a better way of classifying theory in IS?}

The taxonomy offered relies on the goals of a theory as the primary attribute on which to distinguish among classes of theories. The goal-related characteristics of theory are mentioned in many definitions of theory to varying degrees and thus appear to be a natural place to start in constructing a taxonomy. The only other structural characteristic identified as a possible candidate for distinguishing among theories is the level of generality. This characteristic is seen as of secondary importance to the goal, but could be used if a twodimensional classification schema was attempted. Further subclassifications within the types could possibly be attempted. Structural attributes have been used as the primary classifier for the taxonomy, rather than socio-technical or epistemological distinctions. A classification schema that relies on attributes of different types at the same level can be problematic. If classification is attempted on nonstructural grounds, then it should be done separately.

This essay did not have a great deal to build on in taxonomic terms and it does not claim to be the final word on theory classification. There may be a number of other ways of classifying theory, or theory categories that can sensibly be added to the current taxonomy. Further, only a limited number of examples could be given for each theory type and attempts to classify a larger number of examples might reveal further subcategories of interest.

\section{Should one type of theory precede the other?}

The discussion of the interrelationships among the theory types suggests that one type of theory could lead to theory development of another type. Certainly, the components of theory Type I are necessary before theory of other types can be expressed clearly. The different types of theory, however, could each have many origins. The development of theory or conjectures in the first place can occur as a result of observations of what occurs in the real world (Godfrey-Smith 2003; Nagel 1979) or from insights or imagination or problems or feelings (Popper 1980). Construction of an artifact and Type $\mathrm{V}$ theory can spring from inventiveness and imagination, ahead of good knowledge of supporting theory of other types.

\section{Are these five theory types unique to IS?}

This question is difficult. The exploration in this essay has been done from an IS viewpoint, based on the underlying philosophy of enquiry in areas that are seen as relevant to IS: the natural sciences, the social sciences, and the sciences of the artificial. Other fields have a similar base and possibly similar types of theory could be detected; for example, in economics, accounting, management, engineering, or architecture. In none of these fields, however, are there artifacts of the same type that are so squarely at the intersection of human and machine behavior. Thus, it is possible that none of these other fields needs to draw so strongly on each of the physical and the behavioral sciences and the sciences of the artificial, 
nor that they are so much in need of an integrative view of theory. In addition, it is possible that further exploration of theory for design and action will show that it takes on a unique form for IS artifacts (Gregor and Jones 2004).

Writers in other disciplines have not considered the range in theory types that has been recognized here. DiMaggio (1995), Weick (1995), and others in the social sciences do not discuss theory for design and action. Simon (1996) considered design science and natural science models but not others. Nagel (1979) discusses natural and social science theory but not design science. To sum up, it appears the mix of theory types in which IS has a strong interest gives us a distinctive character. The strong theory that we can aim at, which includes all five theory types, will be a unique product of IS.

\section{Concluding Remarks}

This essay began with an examination of basic problem areas in conceptualizing theory: causality, explanation, prediction, and generality. Using the goals of theory as a primary means of classification, five interrelated types of theory were distinguished for IS: (1) theory for analyzing, (2) theory for explaining, (3) theory for predicting, (4) theory for explaining and predicting (EP), and (5) theory for design and action. The basic building blocks of theory have been shown to include the necessary components of means of representation, constructs, relationships between constructs and the specification of the scope of the theory. In addition, components that vary depending on the nature of the theory include causally based explanations (as opposed to covering-law explanations), verifiable statements (testable propositions), and prescriptive statements. Examples of each theory type have been presented and it has been shown that there are both proponents and opponents for the attachment of the label theory to each class.

There are some potential limitations to the essay. The disciplinary areas included for examination were the natural sciences, the social sciences and the sciences of the artificial. There are other disciplines with different traditions that are also relevant but were excluded from this initial exploration. These disciplines include art, design, architecture, computer science, law, and mathematics. Mathematics, logic, and computer science have long been contributors to the foundations of Information Systems. Art and design could be relevant if we think of the design process for IS as being a creative activity. A further limitation to any essay of this type is the difficulty in presenting very complex philosophical issues in a limited space. Readers are referred for more in-depth treatments to recent examinations of the philosophy of science (for example, Godfrey-Smith 2003) and the excellent anthology of original writings on philosophy and technology compiled by Scharff and Dusak (2003).

The essay makes contribution at several levels. Novice researchers should benefit from the depiction of the basic components of theory, helping with their question of "What is theory?" The approach recommended for theory development is to begin with the research problem and research questions and then determine which type of theory is appropriate for the problem, given the current state of knowledge in the area and using the classes depicted here as a guide. An epistemological approach and research methods are then chosen as a further step. Whether one regards oneself as a positivist or an interpretivist or a scientist should not be the primary question and indeed this categorization may not make much sense, given the simplistic and inconsistent manner in which these terms are often used. It is suggested that researchers should think very carefully and separately about issues such as causality, explanation, generalization, and prediction in framing theory. With the realization that stronger theory can result from combining theory of different types, researchers should keep in mind the potential of their own theory to combine with other types.

A further contribution of the essay is the support for the legitimization of each of the five classes of theory. We can see that views on what constitute theory vary considerably and it is possible that our journal editors, reviewers, and authors are not aware of this divergence in views, or that their own view of theory may differ considerably from that of others. Recognition that there are diverging views on the nature of process-type and variance-type theories and also that Type IV theory can combine both process and variance aspects is particularly important. Hopefully the arguments in this essay can be used as justification by researchers for the value of their own theory types.

Finally this essay, in addressing the structural nature of IS theory, addresses an aspect of IS research that has been given scant attention in comparison with discussion of our disciplinary domain, epistemological approaches, and sociopolitical issues. If it can provoke further attention to this aspect of our research endeavors, then it will fulfil a useful purpose. The lingering remnants of logical positivist thought that accord with the omission of causal reasoning from theoretical statements should be explicitly confronted and we should be very careful with our language in proposing theory, for example, in differentiating between generality and predictive power, in defining the scope of a theory, and in the wording of propositions. 
As this essay had relatively little prior work on which to build, there are many opportunities for further work. Each of the theory types could be analyzed in more detail, both for structural characteristics and for instances of work performed. The components of the theory types have been described in fairly general terms. More precision could be attempted by specifying the components in terms of symbolic logic or by structuring each type according to Toulmin's model of argumentation (Toulmin et al. 1979), which contains very similar constructs and gives a useful model of everyday reasoning. Cross-classification of each theory type in terms of level of generality could be attempted. Empirical investigation of trends in producing theory of different types could be undertaken. Each of the issues of causality, explanation, and prediction could be analyzed in greater depth with the aim of making argument about these issues more accessible to IS researchers, as Lee and Baskerville (2003) have done with the issue of generalizability.

To conclude, this essay was motivated by the perception that a fresh approach to the foundations and identity of our discipline is needed, focusing on the nature of our theory as a fundamental issue. Information Systems is a new discipline and many of us come from very different backgrounds--from physics, chemistry, mathematics, psychology, management, sociology, philosophy, and computer science. We need a language of our own to talk about theory and should not adopt uncritically ideas about what constitutes theory from any one other disciplinary area. The nature of theory in itself is at least as important as domain, epistemological and sociopolitical questions, which to date have attracted a disproportionate share of the discussion of IS research. A common language to discuss the nature of our theories should facilitate the building of sound, cumulative, integrated, and practical bodies of theory in IS.

\section{Acknowledgments}

Thank you to Allen S. Lee and the reviewers who have helped a great deal in improving this paper. Thanks are also due to the many friends and colleagues who have commented on earlier versions of the paper. Particular thanks are due to $\mathrm{M}$. Lynne Markus, who has been generous in her support, and to Robert Johnston, for his motivating arguments.

\section{References}

Achinstein, P. The Nature of Explanations, Oxford University Press, New York, 1983.

Agre, P. "Computational Research on Interaction and Agency," Artificial Intelligence (72:1), 1995, pp. 1-52.
Ashby, W. R. An Introduction to Cybernetics, Chapman \& Hall, London, 1956.

Audi, R. (ed.). The Cambridge Dictionary of Philosophy ( $2^{\text {nd }}$ ed..), Cambridge University Press, Cambridge, UK, 1999.

Avison, D., Gregor, S., and Wilson, D. "Managerial IT Unconsciousness," Communications of the ACM(49:7), July 2006, pp. 88-93.

Avison, D., and Wood-Harper, T. Multiview: An Exploration in Information Systems Development, McGraw-Hill, Maidenhead, UK, 1990.

Bacharach, S. B. "Organizational Theories: Some Criteria for Evaluation," Academy of Management Review (14:4), 1989, pp. 496-515.

Baskerville, R., and Wood-Harper, A. T. "Diversity in Information Systems Action Research Methods," European Journal of Information Systems (7:2), 1998, pp. 90-107.

Benbasat, I. "Editorial Notes," Information Systems Research (12:2), 2001, pp. iii-iv.

Benbasat, I., and Weber, R. "Research Commentary: Rethinking 'Diversity' in Information Systems Research," Information Systems Research (7:4), 1996, pp. 389-399.

$\rightarrow$ Benbasat, I., and Zmud, R. "The Identity Crisis Within the IS Discipline: Defining and Communicating the Discipline's Core Properties," MIS Quarterly (27:2), 2003, pp. 183-194.

$\rightarrow$ Bhattacherjee, A., and Premkumar, G. "Understanding Changes in Belief and Attitude Towards Information Technology Usage: A Theoretical Model and Longitudinal Test," MIS Quarterly (28:2), 2004, pp. 229-254.

Burstein, F., and Gregor, S. "The Systems Development or Engineering Approach to Research in Information Systems: An Action Research Perspective," in Proceedings of the $10^{\text {th }}$ Australasian Conference on Information Systems, B. Hope and P. Yoong (eds.), Victoria University of Wellington, New Zealand, 1999, pp. 122-134.

Codd, E. F. "A Relational Model of Data for Large Shared Data Banks," Communications of the ACM (13:6), 1970, pp. 377-387.

Cook, T. D., and Campbell, D. T. Quasi-Experimentation Design and Analysis Issues for Field Settings, Houghton Mifflin, Boston, MA, 1979.

Craik, K. The Nature of Explanation, Cambridge University Press, Cambridge, UK, 1943.

Cross, N. "Design/Science/Research: Developing a Discipline," paper presented at the Fifth Asian Design Conference: International Symposium on Design Science, Su Jeong Dang Printing Company, Seoul, Korea 2001.

Cushing, B. E. "Frameworks, Paradigms and Scientific Research in Management Information Systems," Journal of Information Systems (4:2), 1990, pp. 38-59.

Davis, F. D. "Perceived Usefulness, Perceived Ease-of-Use, and User Acceptance of Information Technology," MIS Quarterly (13:3), 1989, pp. 319-340.

Davis, F. D. A Technology Acceptance Model for Empirically Testing New End-user Information Systems: Theory and Results, unpublished Doctoral Dissertation, Sloan School of Management, Massachusetts Institute of Technology, 1986. 
$\rightarrow$ Davis, F. D., Bagozzi, R., and Warshaw, P. "User Acceptance of Computer Technology: A Comparison of Two Theoretical Models," Management Science (35:8), 1989, pp. 982-1003.

Davis, G. B. "Information Systems Conceptual Foundations: Looking Backward and Forward," in Organizational and Social Perspectives on Information Technology, R. Baskerville, J. Stage, and J. I. DeGross (eds.), Kluwer Academic Publishers, Boston 2000, pp. 61-82.

Davis, G. B., and Olson, M. H. Management Information Systems: Conceptual Foundations, Structure and Development ( $\left.2^{\text {nd }} \mathrm{ed}.\right)$, McGraw-Hill, New York, 1985.

$\rightarrow$ DeLone, W. H., and McLean, E. R. "The DeLone and Mclean Model of Information System Success: A Ten-Year Update," Journal of Management Information Systems (19:4), Spring 2003, pp. 9-30.

DeLone, W. H., and McLean, E. R. "Information Systems Success: The Quest for the Dependent Variable," Information Systems Research (3:1), 1992, pp. 60-95.

Denzin, N. K., and Lincoln, Y. S (eds.). Handbook of Qualitative Research, Sage, Thousand Oaks, CA, 1994.

DiMaggio, P. J. "Comments on 'What Theory is Not'," Administrative Sciences Quarterly (40:3), 1995, pp. 391-397.

Doty, D. H., and Glick, W. H. "Typologies as a Unique Form of Theory Building: Towards Improved Understanding and Modeling," Academy of Management Review 19(2), 1994, pp. 230-251.

Dubin, R. Theory Building (Rev. ed.), Free Press, London, 1978.

Duhem, P. The Aim and Structure of Physical Theory, Atheneum, New York, 1962.

Fawcett, J., and Downs, F. S. The Relationship of Theory and Research, Appleton-Century-Crofts, Norwalk, CT, 1986.

Foucault, M. Les Mots et les Choses. Une Archeologie des Sciences Humaines, Gallimard, Paris, translated by A. Sheridan as the The Order of Things: An Archaeology of the Human Sciences, Tavistock Publications, London, 1971.

Freese, L. "Formal Theorizing," Annual Review of Sociology (6), 1980, pp. 187-212.

Friedman, M. Essays in Positive Economics, University of Chicago Press, Chicago, 1953.

Friedman, M. "Explanation and Scientific Understanding," Journal of Philosophy (71:1), 1974, pp. 5-19.

Gane, C., and Sarson, T. Structured Systems Analysis: Tools and Techniques, Prentice-Hall, Englewood Cliffs, NJ, 1979.

Giddens, A. The Constitution of Society, Polity Press, Cambridge, $\mathrm{UK}, 1984$.

Glaser, B. G., and Strauss, A. L. The Discovery of Grounded Theory: Strategies for Qualitative Research, Aldine Publishing Company, Chicago, 1967.

Godfrey-Smith, P. Theory and Reality, University of Chicago Press, Chicago, 2003.

Goode, S. "Organizational Size Metrics in IS Research: A Critical Survey of the Literature 1989-2000," in Proceedings of the $12^{\text {th }}$ Australasian Conference on Information Systems, G. Finnie, D. Cecez-Kecmanovic, and B. Lo (eds.), Coffs Harbour, Australia, December 4-7, 2001, pp. 257-268.
Goode, S. "On the Theoretical Justification of the Organizational Size Construct in Information Systems Research," in Proceedings of $6^{\text {th }}$ Pacific Asia Conference on Information Systems, The Japan Society for Management Information, Tokyo, Japan, 2002.

Gorry, G. A., and Scott Morton, M. S. "A Framework for Management Information Systems," Sloan Management Review (13:1), 1971, pp. 55-70.

Gregor, S. "Design Theory in Information Systems," Australian Journal of Information Systems, Special Issue 2002a, pp. 14-22.

Gregor, S. "A Theory of Theories in Information Systems," in Information Systems Foundations: Building the Theoretical Base, S. Gregor and D. Hart (eds.), Australian National University, Canberra, 2002b, pp. 1-20.

$\rightarrow$ Gregor, S., and Benbasat, I. "Explanations from Intelligent Systems: Theoretical Foundations and Implications for Practice," MIS Quarterly (23:4), 1999, pp. 497-530.

Gregor S., and Jones, D. "The Formulation of Design Theories," in Constructing the Infrastructure for the Knowledge Economy: Methods and Tools, Theory and Practice, H. Linger, J. Fisher, W. Wojtkowski, J. Zupancic, K. Vigo, and J. Arold (eds.), Kluwer Academic Publishers, Boston, 2004, pp. 83-93.

Gribbin, J. Science: A History 1543-2001, Allen Lane, Camberwell, Victoria, Australia, 2002.

Guba, E. G., and Lincoln, Y. "Competing Paradigms in Qualitative Research," in Handbook of Qualitative Research, N. K. Denzin, and. Y.S. Lincoln (eds.), Sage Publications, Thousand Oaks, CA, 1994, pp. 105-117.

Habermas, J. Theory of Communicative Action, Volume 1: Reason and the Rationalization of Society, Heinemann, London, UK, 1984.

Hempel, C. G., and Oppenheim, P. "Studies in the Logic of Explanation," Philosophy of Science (15), 1948, pp. 135-175.

$\rightarrow$ Hevner, A., March, S., Park, J., and Ram, S. "Design Science in Information Systems Research," MIS Quarterly (28:1), 2004, pp. 75-105.

Hitt, L., and Bryjolfsson, E. "Productivity, Business Profitability and Consumer Surplus: Three Different Measures of Technology Value," MIS Quarterly (20:2), 1996, pp. 121-142.

Hooker, R. Aristotle: The Four Causes, 1996 (available online at http://www.wsu.edu:8080/ dee/GREECE/4CAUSES.HTM).

Hospers, J. An Introduction to Philosophical Analysis ( $2^{\text {nd }}$ ed.), Routledge and Kegan Paul, London, 1967.

Huber, G., and Van de Ven, A. (eds.). Longitudinal Field Research Methods, Sage Publications, Thousand Oaks, CA, 1995.

Hume, D. "An Enquiry Concerning Human Understanding," 1748. Reprinted in Introduction to Philosophy Classical and Contemporary Readings ( $3^{\text {rd }}$ ed.), J. Perry and M. Bratman (eds.), Oxford University Press, New York, 1999, pp. 190-220.

Iivari, J. Contributions to the Theoretical Foundations of Systemeering Research and the Picoco Model, Institute of Data processing Science, University of Oulu, Oulu, Finland, 1983.

Iivari, J. "A Paradigmatic Analysis of Contemporary Schools of IS Development," European Journal of Information Systems (1:4), 1991, pp. 249-272.

Iivari, J., Hirschheim, R., and Klein, H. K. "A Dynamic Framework for Classifying Information Systems Development 
Methodologies and Approaches," Journal of Management Information Systems (17:3), 2000 -2001, pp. 179-218.

Iivari, J., Hirschheim, R., and Klein, H. K. "A Paradigmatic Analysis Contrasting Information Systems Development Approaches and Methodologies," Information Systems Research (9:2), 1998, pp. 1-30.

Kambil, A., and Van Heck, E. Making Markets: How Firms Can Design and Profit from Online Auctions and Exchanges, Harvard Business School Press, Boston, MA, 2002.

Kant, I. "Critique of Pure Reason," 1781, in Continental Philosophy An Anthology, W. McNeill and K. S. Feldman (eds.), Blackwell, Malden, MA, 1998, pp. 7-23.

Kaplan, A. The Conduct of Enquiry, Harper Row, New York, 1964.

Kerlinger, F. N. Foundations of Behavioural Research ( $2^{\text {nd }} \mathrm{ed}$.), Holt, Rinehart and Winston, New York, 1973.

Kim, J. "Causation," in The Cambridge Dictionary of Philosophy ( $2^{\text {nd }}$ ed.), R. Audi (ed.), Cambridge University Press, Cambridge, UK, 1999, pp. 125-127.

Klein, H., and Myers, M. "A Set of Principles for Conducting and Evaluating Interpretive Field Studies," MIS Quarterly (23:1), 1999, pp. 67-93.

Koppius, O. R. Information Architecture and Electronic Market Performance, ERIM Ph.D. Series Research in Management 13, Erasmus University, Rotterdam, 2002.

Kuhn, T. The Structure of Scientific Revolution, University of Chicago Press, Chicago, 1996.

Kwon, T. H., and Zmud, R. W. "Unifying the Fragmented Models of Information Systems Implementation," in Critical Issues in Information Systems Research, R. J. Boland and R. A. Hirschheim (eds.), John Wiley \& Sons, Chichester, UK, 1987, pp. 227-251.

Latour, B. "Technology is Society Made Durable," in A Sociology of Monsters: Essays on Power, Technology and Domination, J. Law (ed.), Routledge, London, 1991, pp. 103-131.

Lau, F. "A Review on the Use of Action Research in Information Systems Studies," in Information Systems and Qualitative Research, A. S. Lee, L. A. Liebenau and J. I. DeGross (eds.), Chapman \& Hall, London, 1997, pp. 31-68.

$\rightarrow$ Lee, A. "Integrating Positivist and Interpretive Approaches to Organizational Research," Organization Science (2:4), 1991, pp. 342-365.

Lee, A. S. "Editorial," MIS Quarterly (25:1), 2001, pp. iii-vii.

Lee, A. S., and Baskerville, R. L. "Generalizing Generalizability in Information Systems Research," Information Systems Research (14:3), 2003, pp. 221-243.

$\rightarrow$ Lee, B., Barua, A., and Whinston, A. B. "Discovery and Representation of Causal Relationships in MIS: A Methodological Framework," MIS Quarterly (21:1), 1997, pp. 109-134.

Lewin, K. "The Research Centre for Group Dynamics at Massachusetts Institute of Technology," Sociometry (8), 1945, pp. 126135.

Little, D. E. "Philosophy of the Social Sciences," in The Cambridge Dictionary of Philosophy ( $2^{\text {nd }}$ ed.), R. Audi (ed.), Cambridge University Press, Cambridge, UK, 1999, pp. 704-706.

Locke, J. "Essay Concerning Human Understanding," 1689. Reprinted in Introduction to Philosophy Classical and Con- temporary Readings ( $3^{\text {rd }}$ ed.), J. Perry and M. Bratman (eds.), Oxford University Press, New York, 1999, pp. 139-144.

Magee, B. Confessions of a Philosopher, Phoenix, London, 1998.

March, S. T., and Smith, G. F. "Design and Natural Science Research on Information Technology," Decision Support Systems (15), 1995, pp. 251-266.

$\rightarrow$ Markus, M., Majchrzak, L. A., and Gasser, L. "A Design Theory for Systems that Support Emergent Knowledge Processes," MIS Quarterly (26:3), 2002, pp. 179-212.

Markus, M. L., and Robey, D. "Information Technology and Organizational Change: Causal Structure in Theory and Research," Management Science 34(5), 1988, 583-598.

Mayes, G. R. "Theories of Explanation," Internet Encyclopaedia of Philosophy, August 112004 (available online at http://www. utm.edu/research/iep/e/explanat.htm).

McKelvey, B. Organizational Systematics - Taxonomy, Evolution, Classification, University of California Press, Berkeley, CA, 1982.

Merton, R. K. Social Theory Social Structure, Free Press, New York, 1968.

Merton, R. K. Theoretical Sociology, Free Press, New York, 1967.

Miles, M., and Huberman, A. An Expanded Sourcebook Qualitative Data Analysis (2nd ed.), Sage Publications, Thousand Oaks, CA, 1994.

Miles, R. E., and Snow, C. C. Organization, Strategy, Structure and Process, McGraw-Hill, New York, 1978.

Mingers, J. "Combining IS Research Methods: Towards a Pluralist Methodology," Information Systems Research (12:3), 2001, pp. 240-259.

MISQ. MISQ Roadmap. Information for Prospective Authors,. August 2004 (http://www.misq.org/roadmap/standards.html).

Mohr, L. B. Explaining Organizational Behavior the Limits and Possibilities of Theory and Research, Jossey-Bass, San Francisco, CA, 1982.

Moore, G. E. "Cramming More Components onto Integrated Circuits," Electronics (38:8), 1965, pp. 114-117.

Morrison, J., and George, J. F. "Exploring the Software Engineering Component in MIS Research," Communications of the ACM (38:7), 1995, pp. 80-91.

Nagel, E. The Structure of Science, Hackett Publishing Co., Indianapolis, IN, 1979.

Neuman, W. L. Social Research Methods ( $4^{\text {th }}$ ed.), Allyn and Bacon, Boston, 2000.

$\rightarrow$ Ngwenyama, O., and Lee, A. "Communication Richness in Electronic Mail: Critical Social Theory and the Contextuality of Meaning," MIS Quarterly (21:2), 1997, pp. 145-167.

Norton, D. F. "Hume," in The Cambridge Dictionary of Philosophy ( $2^{\text {nd }}$ ed.), R. Audi (ed.), Cambridge University Press, Cambridge, UK, 1999, pp. 398-403.

Nunamaker, J., Chen, M., and Purdin, T. "Systems Development in Information Systems Research," Journal of Management Information Systems (7:3), 1990-91, pp. 89-106.

OED (Oxford English Dictionary) Online, August 102004 (http://dictionary.oed.com). 
Orlikowski, W. J. "The Duality of Technology: Rethinking the Concept of Technology in Organizations," Organization Science (3:3), 1992, pp. 398-427.

Orlikowski, W. J., and Baroudi, J. J. "Studying Information Technology in Organizations: Research Approaches and Assumptions," Information Systems Research (2:1), 1991, pp. 1-28.

Orlikowski, W. J., and Iacono, C. S. "Research Commentary: Desperately Seeking the 'IT' in IT Research-A Call to Theorizing the IT Artifact," Information Systems Research (12:2), 2001, pp. 121-134.

Orlowski, W. J., and Robey, D. "Information Technology and the Structuring of Organizations," Information Systems Research (2:2), 1991, pp. 143-169.

Passmore, J. "Logical Positivism," in Encyclopaedia of Philosophy (Volume V), P. Edwards (ed.), Macmillan, New York, 1967, pp. 52-57.

Pearl, J . Causality: Models, Reasoning and Inference, Cambridge University Press, Cambridge, UK, 2000.

Popper, K. Conjectures and Refutations ( $3^{\text {rd }}$ ed.), Routledge Classics, London, 2002.

Popper, K. The Logic of Scientific Discovery, Unwin Hyman, London, 1980.

Popper, K. Logik der Forschung, Julius Springer, Vienna, 1934.

Popper, K. Unended Quest an Intellectual Autobiography, Fontana, Glasgow, 1986

Robey, D. "Research Commentary: Diversity in Information Systems Research: Threat, Promise, and Responsibility," Information Systems Research (7:4), 1996, pp. 400-408.

Rogers, E. M. Diffusion of Innovations. ( $4^{\text {th }} \mathrm{ed}$.), The Free Press, New York, 1995.

Scharff, R., and Dusak, V. (eds.). Philosophy of Technology: The Technological Condition An Anthology, Blackwell, Malden, MA, 2003.

Schwandt, I. A. "Constructivist, Interpretivist Approaches to Human Inquiry," in Handbook of Qualitative Enquiry, N. K. Denzin and Y. S. Lincoln (eds.), Sage Publications, Thousand Oaks, CA, 1994, pp. 118-137.

Seddon, P. "A Respecification and Extension of the DeLone and McLean Model of IS Success," Information Systems Research (8:3), 1997, pp. 240-251.

Shannon, C. "A Mathematical Theory of Communication," The Bell System Technical Journal (27), July/October 1948, pp. 379-423/623-656.

Simon, H. The Sciences of the Artificial ( $3^{\text {rd }}$ ed.), MIT Press, Cambridge, MA, 1996.

Simpson, G. G. Principles of Animal Taxonomy, Columbia University Press, New York, 1961.

Sommerville, I. Software Engineering ( $6^{\text {th }}$ ed.), Addison-Wesley, Harlow, England, 2001.

Sutton, R. I., and Staw, B. M. "What Theory is Not," Administrative Sciences Quarterly (40:3), 1995, pp. 371-384.

Toulmin, S. The Uses of Argument, Cambridge University Press, Cambridge, UK, 1958.

Toulmin, S., Rieke, R., and Janik, A. An Introduction to Reasoning, Macmillan, New York, 1979.
Turban, E., and Aronson, J. Decision Support Systems and Intelligent Systems, Prentice-Hall, Upper Saddle River, NJ, 2001.

Von Bertalanffy, L. General System Theory (Rev. ed.), George Braziller, New York, 1973.

Walls, J. G., Widmeyer, G. R., and El Sawy, O. A. "Building an Information System Design Theory for Vigilant EIS," Information Systems Research (3:1), 1992, pp. 36-59.

Walsham, G. "Interpretative Case Studies in IS Research: Nature and Method," European Journal of Information Systems (4:2), 1995, pp. 74-81.

Watson, R. "Research in Information Systems: What We Haven't Learned," MIS Quarterly (25:4), 2001, pp. v-xv.

Weber, R. "Toward a Theory of Artifacts: A Paradigmatic Base for Information Systems Research," Journal of Information Systems (1:2), Spring 1987, pp. 3-19.

Weber, R. "Editor's Comments," MIS Quarterly, (27:2), 2003, pp. iii-xi.

Weber, R. “Editor's Comments,” MIS Quarterly, (28:1), 2004, pp. iii-xii.

Weber, R. Ontological Foundations of Information Systems, Coopers \& Lybrand, Melbourne, Victoria, Australia, 1997.

Weick, K. E. "Theory Construction as Disciplined Imagination," Academy of Management Review (14:4), 1989, pp. 516-531.

Weick, K. E. "What Theory Is Not, Theorizing Is," Administrative Sciences Quarterly (40:3), 1995, pp. 385-390.

Wordsworth. Wordsworth Dictionary of Biography. Wordsworth Editions Ltd, Hertfordshire, UK 1994.

Yin, R. K. Case Study Research Design and Methods ( $2^{\text {nd }}$ ed.), Sage Publications, Thousand Oaks, CA 1994.

\section{About the Author}

Shirley Gregor is the ANU Endowed Chair in Information Systems at the Australian National University, Canberra, where she heads the National Centre for Information Systems Research and is Head of the School of Accounting and Business Information Systems. Professor Gregor's current research interests include the adoption and strategic use of information and communications technologies, intelligent systems and human-computer interface issues, and the theoretical foundations of information systems. Professor Gregor spent a number of years in the computing industry in Australia and the United Kingdom before beginning an academic career. She has published in journals including MIS Quarterly, International Journal of Electronic Commerce, International Journal of Human Computer Studies, European Journal of Information Systems, and Information Technology \& People. Professor Gregor was inaugural President of the Australasian Association of Information Systems 2002-2003 and was made an Officer of the Order of Australia in the Queen's Birthday Honours list in June 2005 for services as an educator and researcher in the field of Information Systems and for the development of applications for electronic commerce in the agribusiness sector. 


\section{Appendix}

\section{Classification of Recent Research Articles}

Only research articles and research notes are included. Issues and opinions, reviews, and research essays are excluded.

\begin{tabular}{|c|c|c|c|}
\hline $\begin{array}{l}\text { Journal } \\
\text { Issue }\end{array}$ & Title of Research Article & Author(s) & Theory Type \\
\hline \multicolumn{4}{|c|}{ MIS Quarterly } \\
\hline \multirow[t]{5}{*}{ March 2003} & $\begin{array}{l}\text { Predicting Intention to Adopt Interorganizational } \\
\text { Linkages: An Institutional Perspective }\end{array}$ & H. H. Teo, K. K. Wei, and I. Benbasat & IV - EP \\
\hline & $\begin{array}{l}\text { Trust and TAM in Online Shopping: An Integrated } \\
\text { Model }\end{array}$ & $\begin{array}{l}\text { D. Gefen, E. Karahanna, and D. W. } \\
\text { Straub }\end{array}$ & IV - EP \\
\hline & $\begin{array}{l}\text { Understanding the Service Component of Application } \\
\text { Service Provision: An Empirical Analysis of } \\
\text { Satisfaction with Asp Services }\end{array}$ & $\begin{array}{l}\text { A. Susarla, A. Barua, and A. B. } \\
\text { Whinston }\end{array}$ & IV - EP \\
\hline & $\begin{array}{l}\text { Issues in Linking Information Technology Capability to } \\
\text { Firm Performance }\end{array}$ & R. Santhanam and E. Hartono & IV - EP \\
\hline & $\begin{array}{l}\text { ClO Lateral Influence Behaviors: Gaining Peers' } \\
\text { Commitment to Strategic Information Systems }\end{array}$ & H. G. Enns, S. L. Huff and C. Higgins & IV - EP \\
\hline \multirow[t]{4}{*}{ June 2003} & $\begin{array}{l}\text { Reconceptualizing Users as Social Actors in Infor- } \\
\text { mation Systems Research }\end{array}$ & R. Lamb and R. Kling & $\begin{array}{l}\text { II - } \\
\text { Explanation }^{1}\end{array}$ \\
\hline & $\begin{array}{l}\text { Shaping Agility Through Digital Options: Reconcep- } \\
\text { tualizing the Role of Information Technology in Con- } \\
\text { temporary Firms }\end{array}$ & $\begin{array}{l}\text { V. Sambamurthy, A. Bharadwaj, and V. } \\
\text { Grover }\end{array}$ & IV - EP \\
\hline & $\begin{array}{l}\text { Virtualness and Knowledge in Teams: Managing the } \\
\text { Love Triangle of Organizations, Individuals, and } \\
\text { Information Technology }\end{array}$ & $\begin{array}{l}\text { T. L. Griffith, J. E. Sawyer, and M. A. } \\
\text { Neale }\end{array}$ & IV - EP \\
\hline & $\begin{array}{l}\text { The Adoption and Use of GSS in Project Teams: } \\
\text { Toward More Participative Processes and Outcomes }\end{array}$ & A. R. Dennis and M. J. Garfield & IV - EP \\
\hline \multirow[t]{4}{*}{$\begin{array}{l}\text { September } \\
2003\end{array}$} & $\begin{array}{l}\text { From the Vendor's Perspective: Exploring the Value } \\
\text { Proposition in Information Technology Outsourcing }\end{array}$ & N. Levina and J. W. Ross & $\begin{array}{l}\text { II - } \\
\text { Explanation }\end{array}$ \\
\hline & $\begin{array}{l}\text { Trust and the Unintended Effects of Behavior Control } \\
\text { in Virtual Teams }\end{array}$ & G. Piccoli and B. Ives & IV - EP \\
\hline & $\begin{array}{l}\text { The Influence of Query Interface Design on Decision- } \\
\text { Making Performance }\end{array}$ & C. Speier and M. G. Morris & IV - EP \\
\hline & $\begin{array}{l}\text { User Acceptance of Information Technology: Toward } \\
\text { a Unified View }\end{array}$ & $\begin{array}{l}\text { V. Venkatesh, M. G. Morris, G. B. } \\
\text { Davis, and F. D. Davis }\end{array}$ & IV - EP \\
\hline
\end{tabular}




\begin{tabular}{|c|c|c|c|}
\hline $\begin{array}{l}\text { Journal } \\
\text { Issue }\end{array}$ & Title of Research Article & Author(s) & Theory Type \\
\hline \multicolumn{4}{|l|}{ MIS Quarterly } \\
\hline \multirow[t]{3}{*}{$\begin{array}{l}\text { December } \\
2003\end{array}$} & $\begin{array}{l}\text { The Contingent Effects of Management Support and } \\
\text { Task Interdependence on Successful Information } \\
\text { Systems Implementation }\end{array}$ & R. Sharma and P. Yetton & IV - EP \\
\hline & $\begin{array}{l}\text { The Value Relevance of Announcements of } \\
\text { Transformational Information Technology Investments }\end{array}$ & $\begin{array}{l}\text { B. Dehning, V. J. Richardson, and R. } \\
\text { W. Zmud }\end{array}$ & IV - EP \\
\hline & $\begin{array}{l}\text { Sources of Influence on Beliefs about Information } \\
\text { Technology Use: An Empirical Study of Knowledge } \\
\text { Workers }\end{array}$ & $\begin{array}{l}\text { W. Lewis, R. Agarwal, and V. } \\
\text { Sambamurthy }\end{array}$ & IV - EP \\
\hline March 2004 & $\begin{array}{l}\text { How Do Suppliers Benefit from Information } \\
\text { Technology Use in Supply Chain Relationships? }\end{array}$ & M. Subramani & IV - EP \\
\hline \multirow[t]{3}{*}{ June 2004} & $\begin{array}{l}\text { GIST: A Model for Design and Management of Con- } \\
\text { tent and Interactivity of Customer-centric Web Sites }\end{array}$ & T. C. Albert, P. B. Goes, and A. Gupta & V - Design \\
\hline & $\begin{array}{l}\text { A Field Study of the Effect of Interpersonal Trust on } \\
\text { Virtual Collaborative Relationship Performance }\end{array}$ & D. L. Paul and R. R. McDaniel Jr. & IV - EP \\
\hline & $\begin{array}{l}\text { Understanding Changes in Belief and Attitude Toward } \\
\text { Information Technology Usage: A Theoretical Model } \\
\text { and Longitudinal Test }\end{array}$ & A. Bhattacherjee and G. Premkumar & IV - EP \\
\hline \multirow{5}{*}{ March 2003} & $\begin{array}{l}\text { XML-Based Schema Definition for Support of } \\
\text { Interorganizational Workflow }\end{array}$ & W. M. P. van der Aalst and A. Kumar & V - Design \\
\hline & $\begin{array}{l}\text { Informational Influence in Organizations: An } \\
\text { Integrated Approach to Knowledge Adoption }\end{array}$ & S. W. Sussman and W. S. Siegal & IV - EP \\
\hline & $\begin{array}{l}\text { When Subordinates Become it Contractors: Persis- } \\
\text { tent Managerial Expectations in IT Outsourcing }\end{array}$ & V. T. Ho, S. Ang, and D. Straub & IV - EP \\
\hline & $\begin{array}{l}\text { The Social Construction of Meaning: An Alternative } \\
\text { Perspective on Information Sharing }\end{array}$ & S. M. Miranda and C. S. Saunders & IV - EP \\
\hline & $\begin{array}{l}\text { Information Goods Pricing and Copyright Enforce- } \\
\text { ment: Welfare Analysis }\end{array}$ & Y. Chen and I. Png & V - Design \\
\hline
\end{tabular}




\begin{tabular}{|c|c|c|c|}
\hline $\begin{array}{l}\text { Journal } \\
\text { Issue }\end{array}$ & Title of Research Article & Author(s) & Theory Type \\
\hline \multicolumn{4}{|c|}{ Information Systems Research } \\
\hline \multirow[t]{4}{*}{ June 2003} & $\begin{array}{l}\text { Measuring Information Technology Payoff: A Meta- } \\
\text { analysis of Structural Variables in Firm-level Empirical } \\
\text { Research }\end{array}$ & R. Kohli and S. Devaraj & IV - EP \\
\hline & $\begin{array}{l}\text { Developing and Validating an Observational Learning } \\
\text { Model of Computer Software Training and Skill } \\
\text { Acquisition }\end{array}$ & M. Y. Yi and F. D. Davis & IV - EP \\
\hline & $\begin{array}{l}\text { The Impact of Experience and Time on the Use of } \\
\text { Data Quality Information in Decision Making }\end{array}$ & $\begin{array}{l}\text { C. W. Fisher, I. Chengalur-Smith, and } \\
\text { D. P. Ballou }\end{array}$ & IV - EP \\
\hline & $\begin{array}{l}\text { A Partial Least Squares Latent Variable Modeling } \\
\text { Approach for Measuring Interaction Effects: Results } \\
\text { from a Monte Carlo Simulation Study and an } \\
\text { Electronic-Mail Emotion/Adoption Study }\end{array}$ & W. Chin, B. Marcolin, p. Newsted & V - Design ${ }^{4}$ \\
\hline \multirow[t]{4}{*}{$\begin{array}{l}\text { September } \\
2003\end{array}$} & $\begin{array}{l}\text { Generalizing Generalizability in Information Systems } \\
\text { Research }\end{array}$ & A. S. Lee and R. L. Baskerville & I-Analysis \\
\hline & $\begin{array}{l}\text { Replicating Online Yankee Auctions to Analyze } \\
\text { Auctioneers' and Bidders' Strategies }\end{array}$ & R. Bapna, P. Goes, and A. Gupta & $\begin{array}{l}\text { III - } \\
\text { Prediction }\end{array}$ \\
\hline & $\begin{array}{l}\text { Improving Analysis Pattern Reuse in Conceptual } \\
\text { Design: Augmenting Automated Processes with } \\
\text { Supervised Learning }\end{array}$ & S. Purao, V. C. Storey, and T. Han & V-Design \\
\hline & $\begin{array}{l}\text { Portfolios of Control in Outsourced Software } \\
\text { Development Products }\end{array}$ & V. Choudhury and R. Sabherwal & $\begin{array}{l}\text { II - } \\
\text { Explanation }\end{array}$ \\
\hline \multirow[t]{3}{*}{$\begin{array}{l}\text { December } \\
2003\end{array}$} & $\begin{array}{l}\text { The Influence of Business Managers' IT Competence } \\
\text { on Championing IT }\end{array}$ & $\begin{array}{l}\text { G. Bassellier, I. Benbasat, and B. } \\
\text { Horner Reich }\end{array}$ & IV - EP \\
\hline & $\begin{array}{l}\text { Synthesis and Decomposition of Processes in } \\
\text { Organizations }\end{array}$ & A. Basu and R. W. Blanning & V-Design \\
\hline & $\begin{array}{l}\text { A Research Note Regarding the Development of the } \\
\text { Consensus on Appropriation Scale }\end{array}$ & C. D. Allport and W. A. Kerler III & I - Analysis \\
\hline \multirow[t]{5}{*}{ March 2004} & $\begin{array}{l}\text { A Fault Threshold Policy to Manage Software } \\
\text { Development Projects }\end{array}$ & I. Robert Chiang and V. S. Mookerjee & V-Design \\
\hline & $\begin{array}{l}\text { Economics of an Information Intermediary with } \\
\text { Aggregation Benefits }\end{array}$ & H. K. Bhargava and V. Choudhary & $V-$ Design \\
\hline & $\begin{array}{l}\text { Building Effective Online Marketplaces with } \\
\text { Institution-Based Trust }\end{array}$ & P. A. Pavlou and D. Gefen & $I V-E P$ \\
\hline & $\begin{array}{l}\text { Does Animation Attract Online Users' Attention? The } \\
\text { Effects of Flash on Information Search Performance } \\
\text { and Perceptions }\end{array}$ & $\begin{array}{l}\text { W. Hong, J. Y. L. Thong, and K. Y. } \\
\text { Tam }\end{array}$ & IV - EP \\
\hline & $\begin{array}{l}\text { A Practice Perspective on Technology-Mediated } \\
\text { Network Relations: The Use of Internet-based Self- } \\
\text { serve Technologies }\end{array}$ & U. Schultze and W. J. Orlikowski & $\begin{array}{l}\text { II - } \\
\text { Explanation }\end{array}$ \\
\hline
\end{tabular}




\begin{tabular}{|c|c|c|c|}
\hline $\begin{array}{l}\text { Journal } \\
\text { Issue }\end{array}$ & Title of Research Article & Author(s) & Theory Type \\
\hline \multicolumn{4}{|c|}{ Information Systems Research } \\
\hline \multirow[t]{5}{*}{ June 2004} & $\begin{array}{l}\text { IT Outsourcing Strategies: Universalistic, Contin- } \\
\text { gency and Configurational Explanations of Success }\end{array}$ & J. Lee, S. M. Miranda and Y. Kim & IV - EP \\
\hline & $\begin{array}{l}\text { Real Options and it Platform Adoption: Implications } \\
\text { for Theory and Practice }\end{array}$ & R. G. Fichman & IV - EP \\
\hline & $\begin{array}{l}\text { An Empirical Analysis of Network Externalities in } \\
\text { Peer-to-Peer Music-Sharing Networks }\end{array}$ & $\begin{array}{l}\text { A. Asvanund, K. Clay, R. Krishnan and } \\
\text { M. D. Smith }\end{array}$ & IV - EP \\
\hline & $\begin{array}{l}\text { Impact of Environmental Uncertainty and Task } \\
\text { Characteristics on User Satisfaction with Data }\end{array}$ & $\begin{array}{l}\text { J. Karimi, T. M. Somers and Y. P. } \\
\text { Gupta }\end{array}$ & IV - EP \\
\hline & $\begin{array}{l}\text { Information Overload and the Message Dynamics of } \\
\text { Online Interaction Spaces: A Theoretical Model and } \\
\text { Empirical Exploration }\end{array}$ & Q. Jones, G. Ravid and S. Rafaeli & IV - EP \\
\hline
\end{tabular}

Notes:

EP = Explanation and Prediction

${ }^{1}$ Classified after discussion. Type I was also considered.

${ }^{2}$ Classified after discussion.

${ }^{3}$ Classified after discussion.

${ }^{4}$ Classified after discussion. A decision was made for Type $\mathrm{V}$ as the paper proposes an improved statistical method.

${ }^{5}$ Classified after discussion. A decision was made for Type III as the paper focuses on a simulation of auction behavior for modeling purposes (prediction). 